التمليل الغنوي لمفهوم 1لالوهية عند بروديكـوسر

\title{
$\left({ }^{*}\right)$
}

طيبة حسين محمد حسين

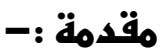

بالرغم من الثهرة التي حظى بها بروديكوس فان تاريخ وأحداث حياته لم

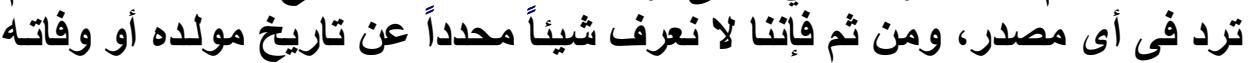

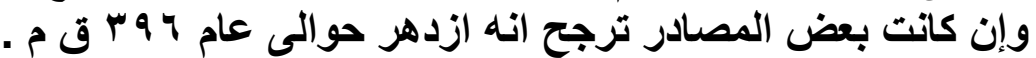

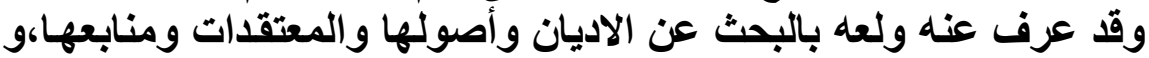

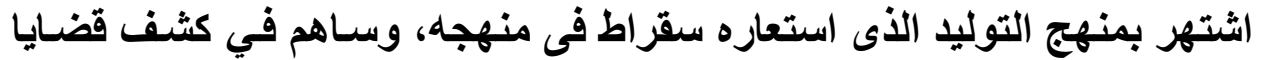

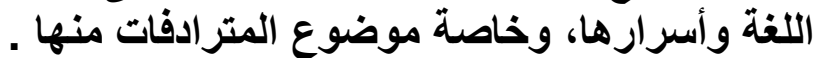

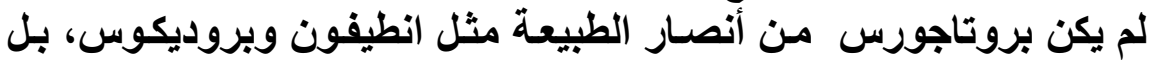

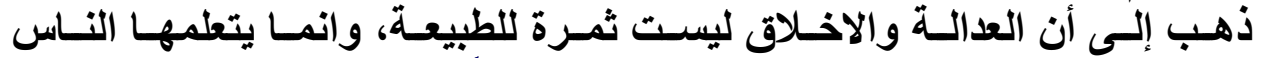

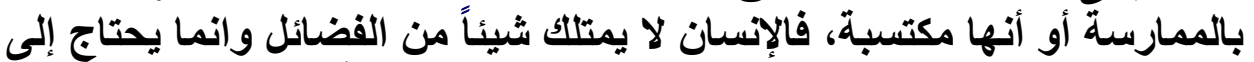

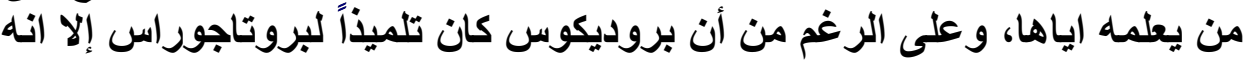

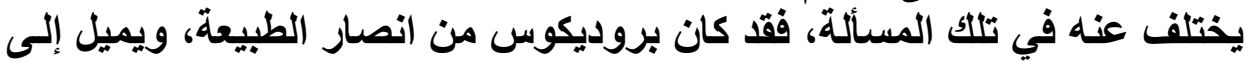

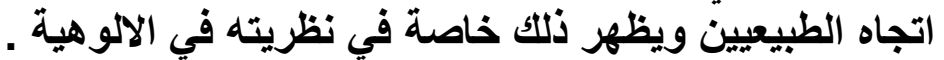

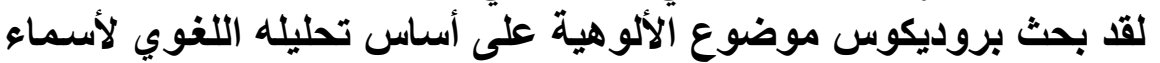

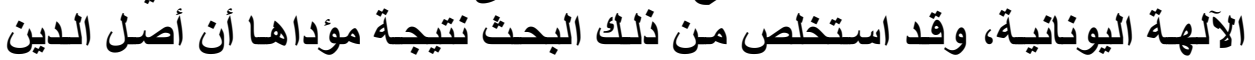

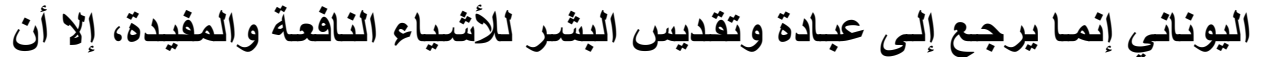

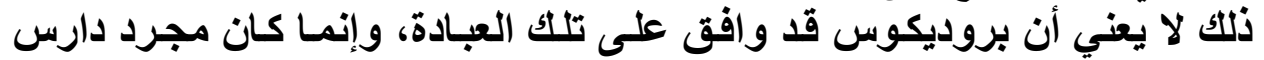
وباحث حول أصل التأليه عند البشر.

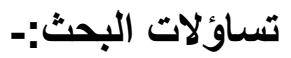

سنحاول من خلال ذلتك البحث الإجابة على تلكك التساؤلات:-

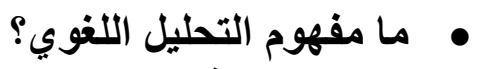

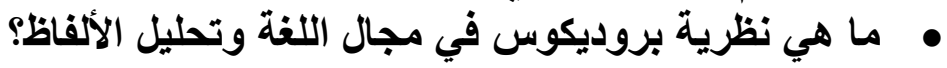

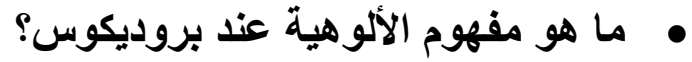

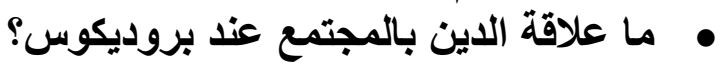

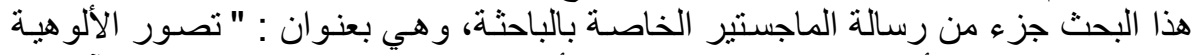

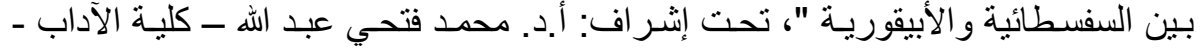

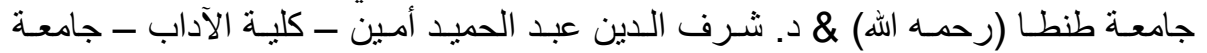


منهمية البهث:- سنتناول ذلك البحث من خلال المنهج التحليلي النقدي. التحليل

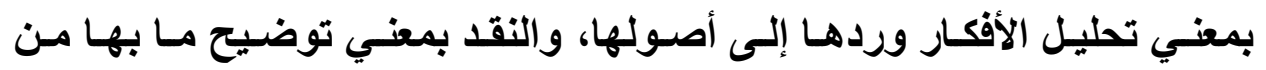
إيجابيات وسلبيات.

\section{عiصاصر البهن:}

ا - معني التحليل اللغوي.

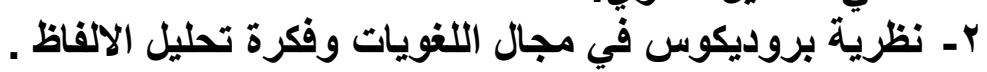

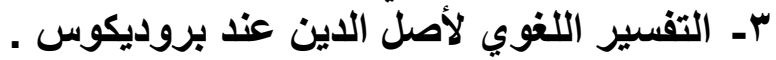

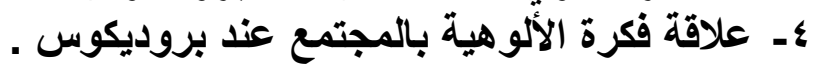

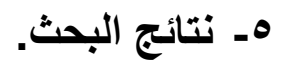

\section{أولا : معنـى التنوليل اللغوي: -}

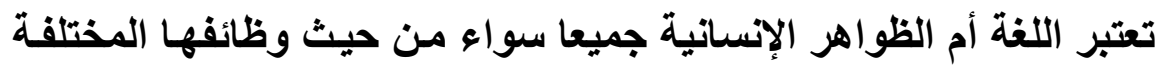

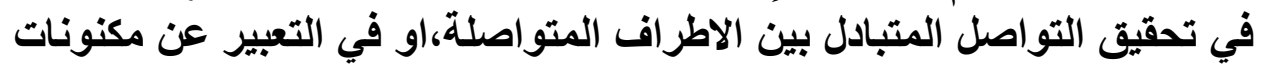

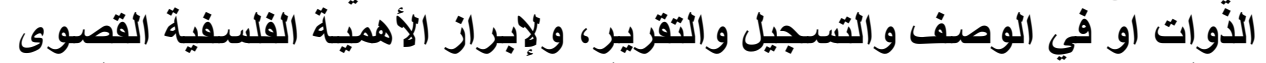

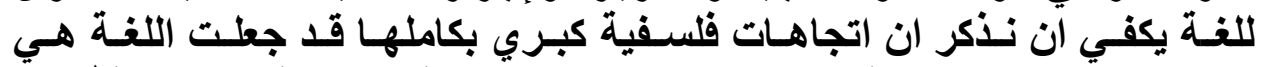

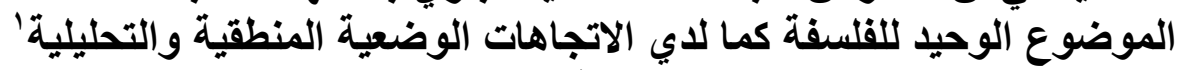

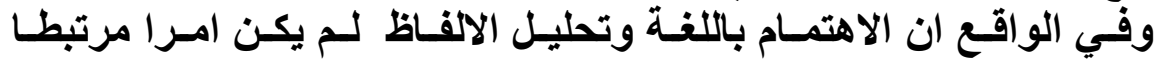

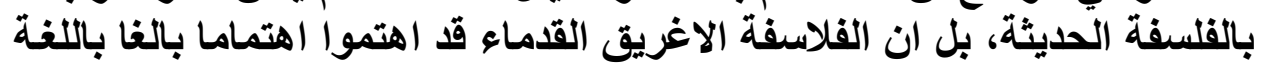

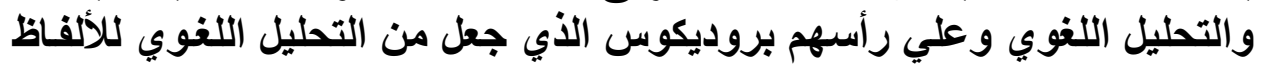

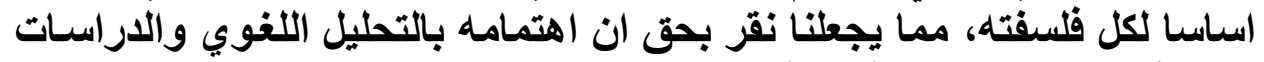

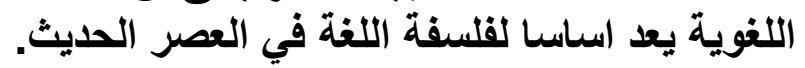

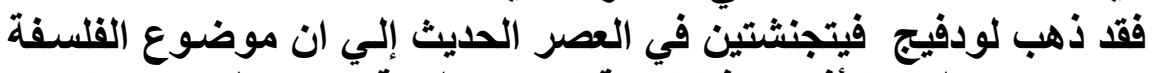

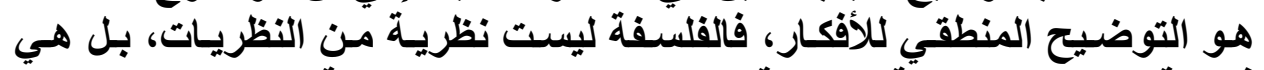

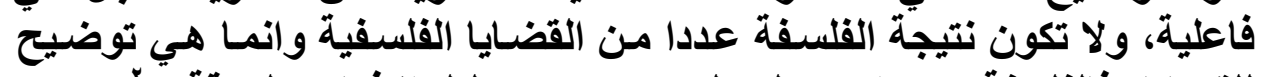

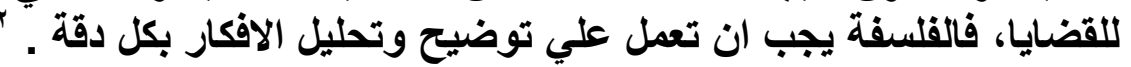

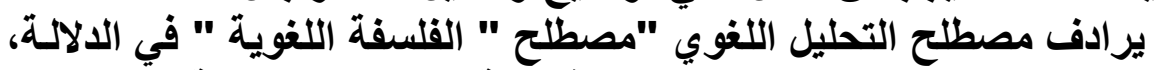
وهو لا يعني سوي " منهج لحل مشكلات فلسفية عن طريق العنايـة بالاستعمال

'ـ محمد سبيلا و عبد السلام بنعبد العالي : دفاتر فلسفيه (نصوص مختاره )، دار توبقال للنشر،

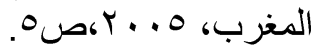
' ـ محمد سبيلا و عبد السلام بنعبد العالي : دفاتر فلسفيه (نصوص مختاره )، ص ؟ 9 $1 \wedge \varepsilon$ 
العادي لكلمات معينة ترتبط بالمشكلة المطروحة للبحث " لـ وفي واقع الأمر هذا

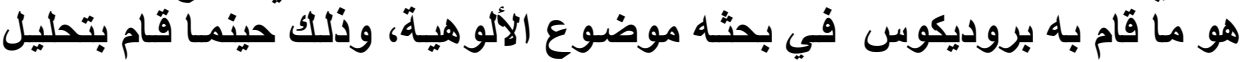

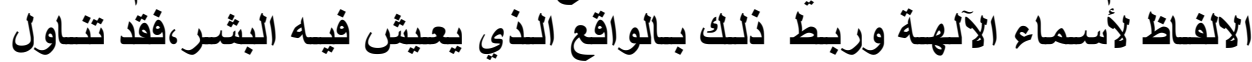

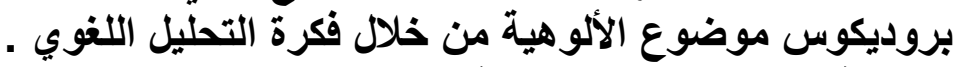

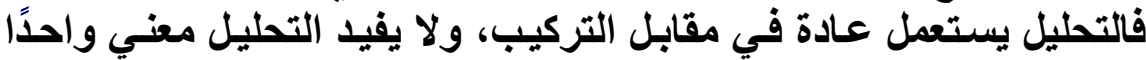

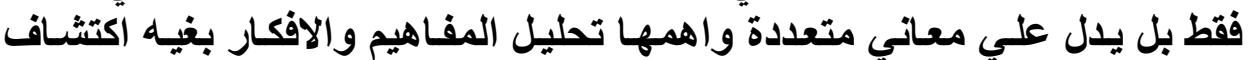

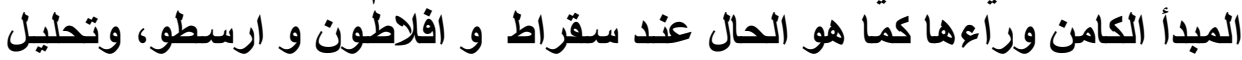

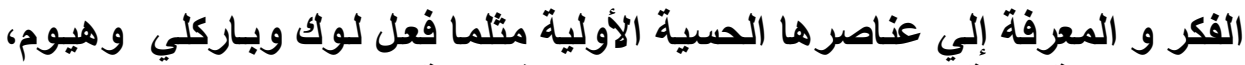

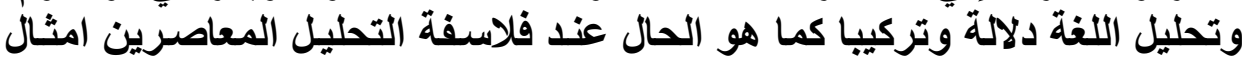

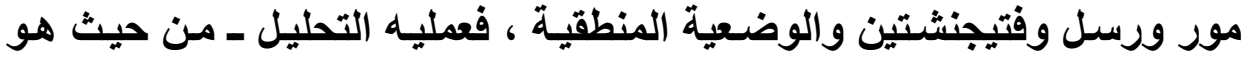

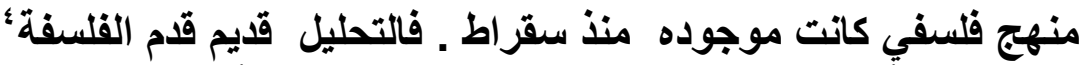

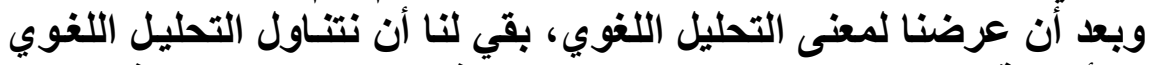

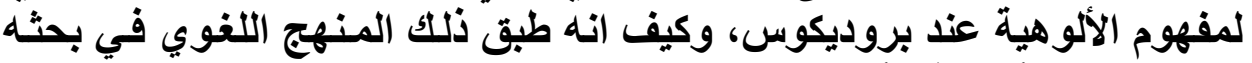

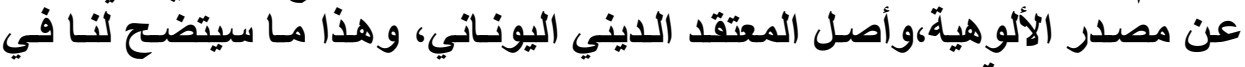

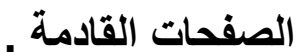

ثانيا :- نظرية بروديكوس في مجال اللغويات وفكرة توفيل وفيل الألفاظ:

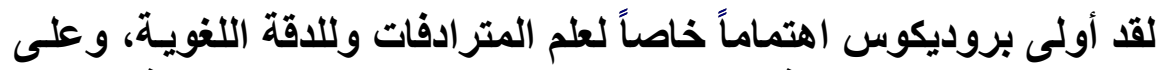
ذلتك يعد مؤسس علم المترادفات Syns

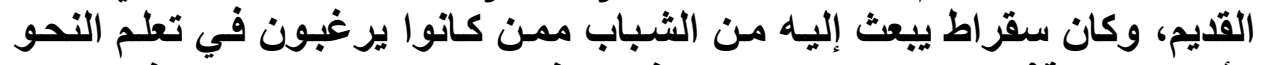

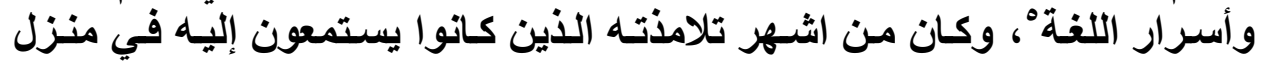

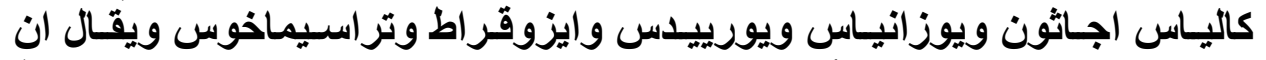

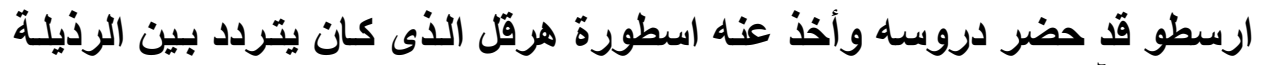

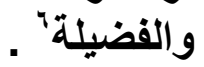

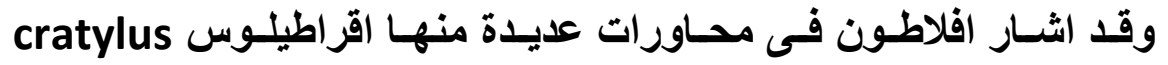
وخارمياس charmides وبروتاجوراس الى تبحر بروديكوس في فنون اللغة

r صلاح اسماعيل عبد الحق : التحليل اللغوي عند مدرسه اكسفورد، دار التتوير للطباعة

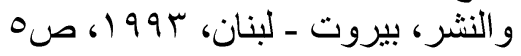

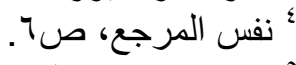

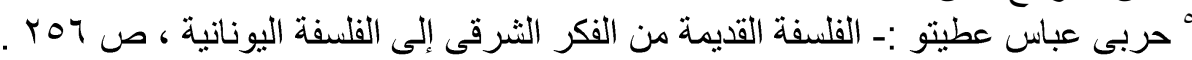

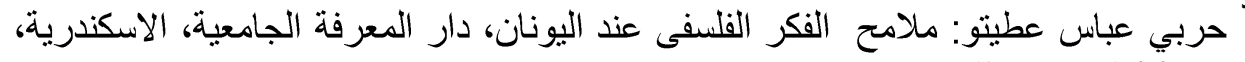
1 10 
وضبط المصطلحات وتطبيقاتها مشيداً بجهوده فى هذا المجال الذى كان يعتبر

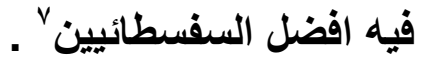

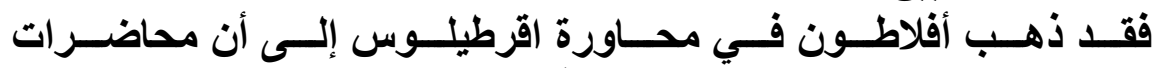

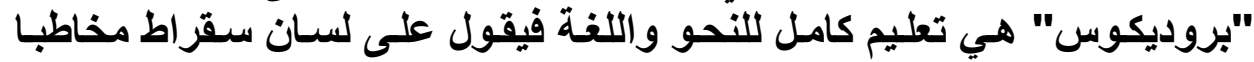

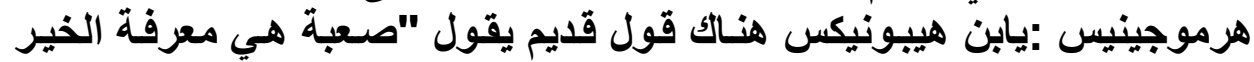

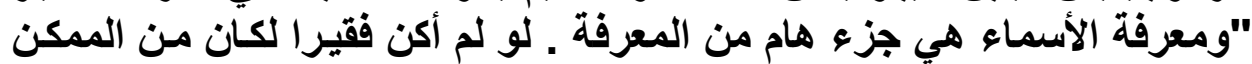

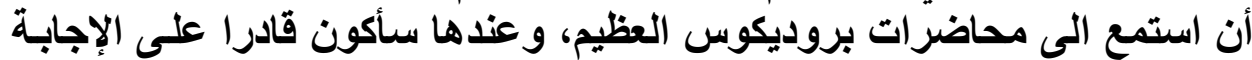

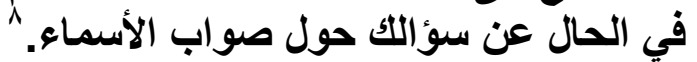

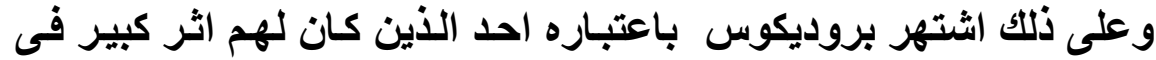

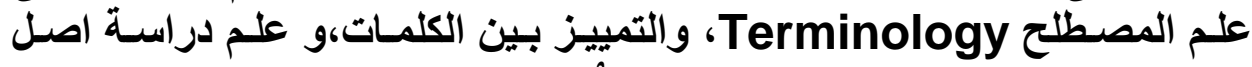

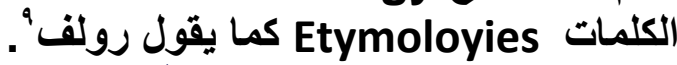

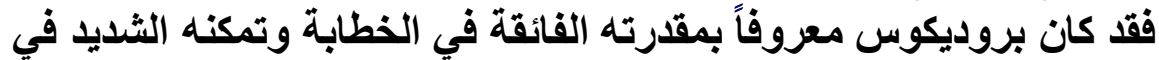

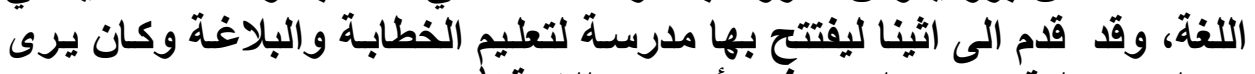

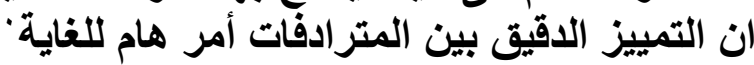

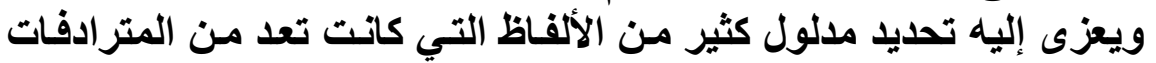

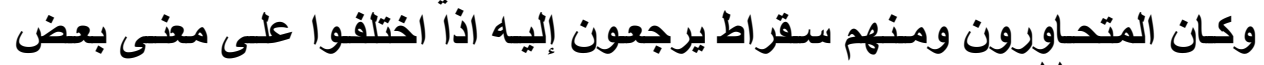
المصطلحات " المنهاورن

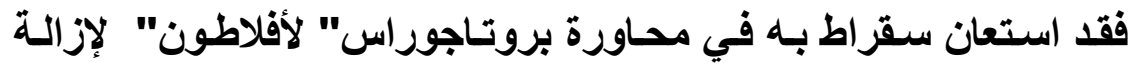

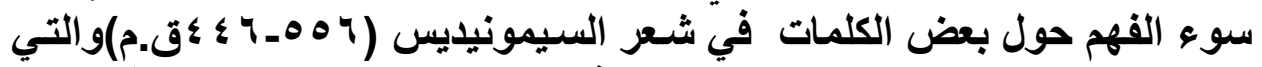

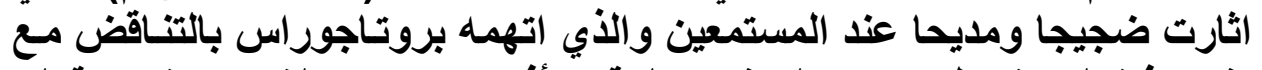

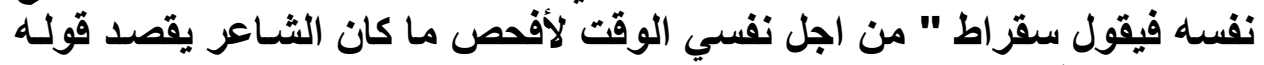

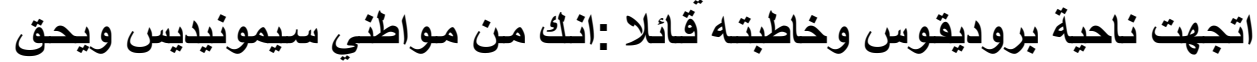

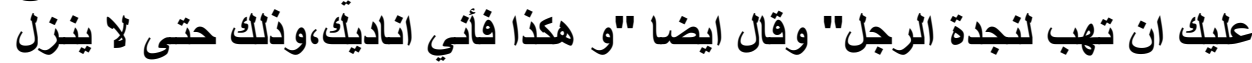

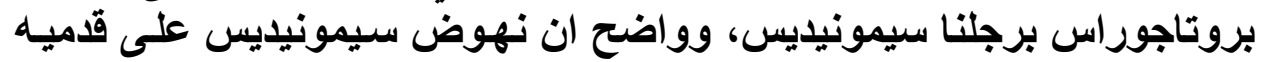

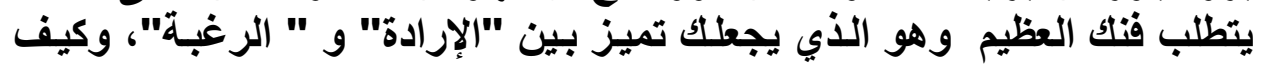

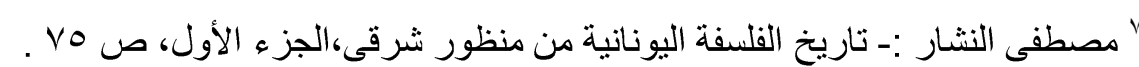

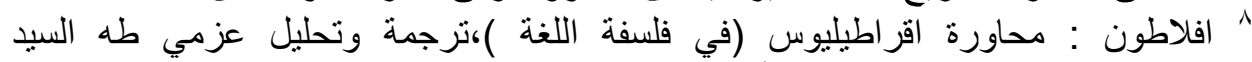

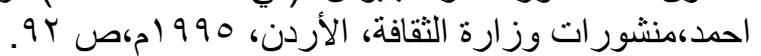
9 شرف الدين عبد الحميد: جدلية العلاقة بين الفلسفة والدارة والدين عند فلاسفة اليونان، دار الوراق

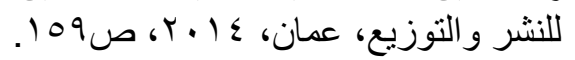

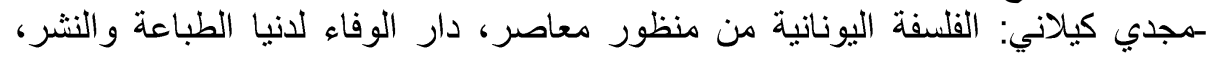

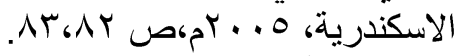
' أحمد فؤاد الأهو اني : فجر الفلسفة اليونانية قبل سقر اط، دار إحياء الكب العربية، 90 1، ص 
انهما ليس شيئا واحدا، هذا الى جاتب تمييزات أخرى كثيرة وجميلة، كالتمييز

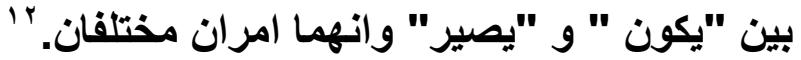

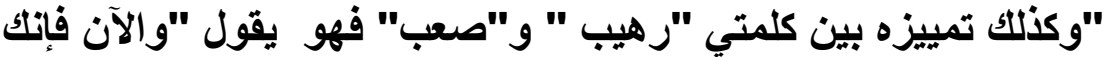

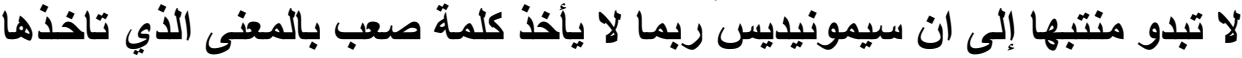

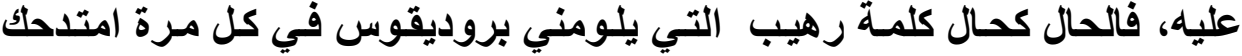

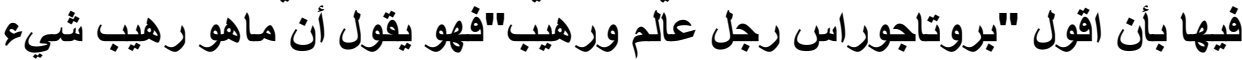

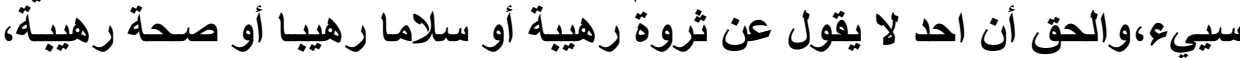

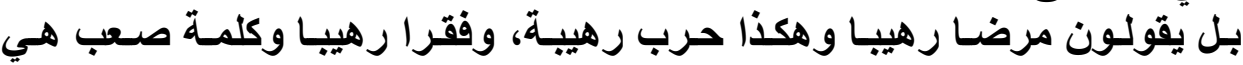

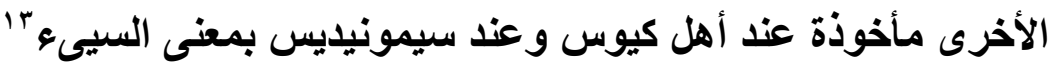

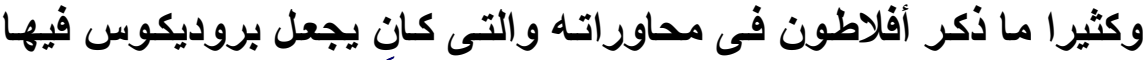

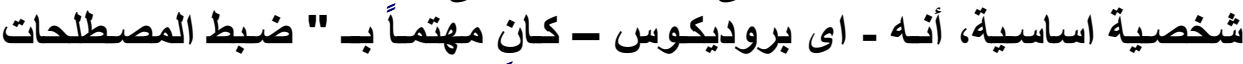
Correct terminology

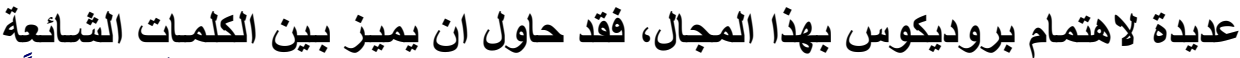

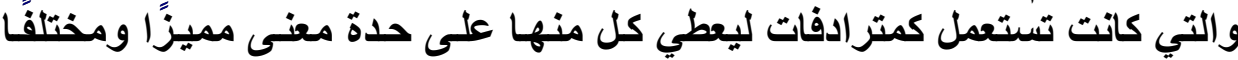

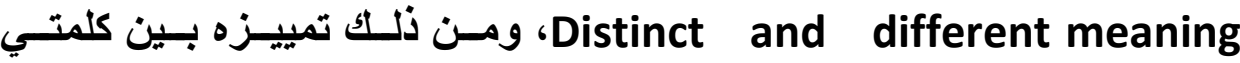

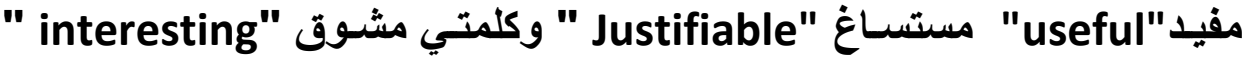

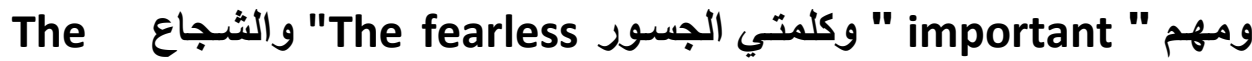

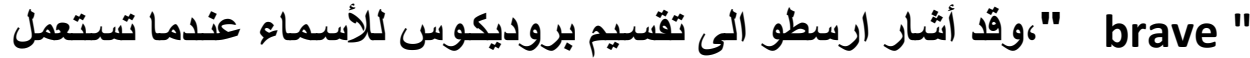

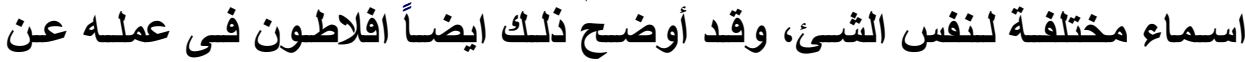

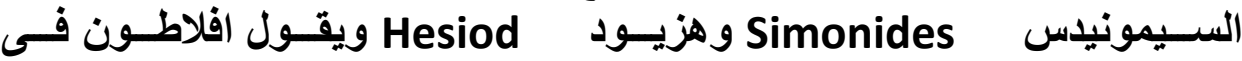
Charmides

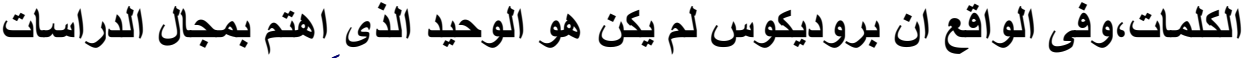

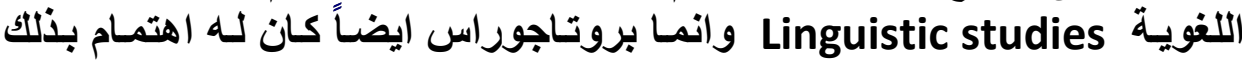

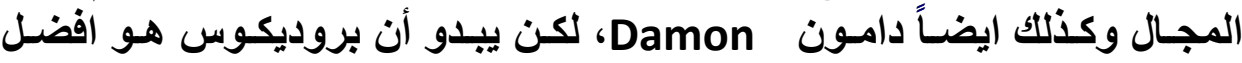

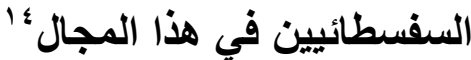

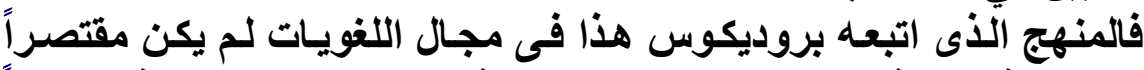

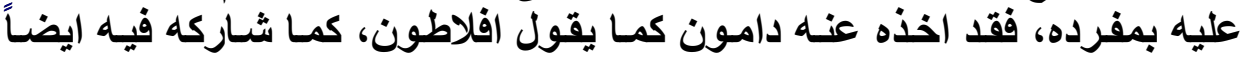

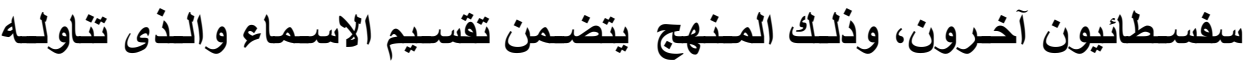

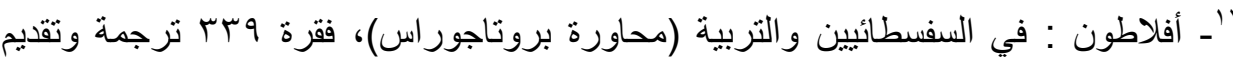

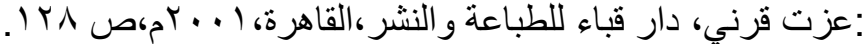

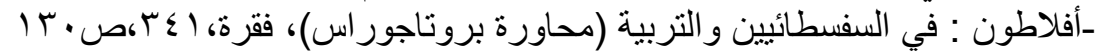

${ }^{14}$ Kathleen freeman:- the pre-Socratic philosophers, Basil Black well ,Oxford, 1959, p.371. 


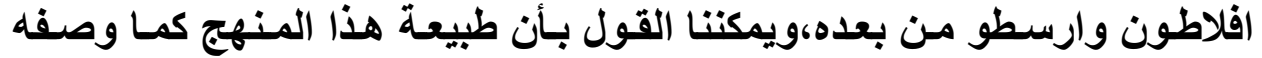

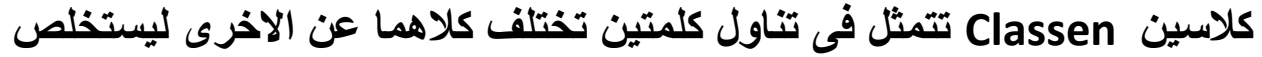

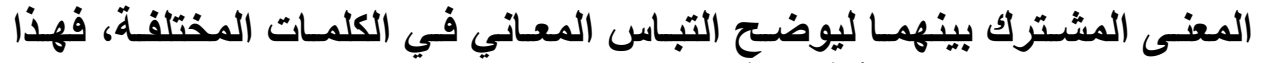

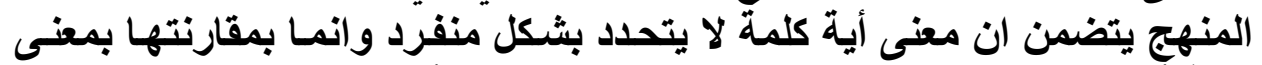

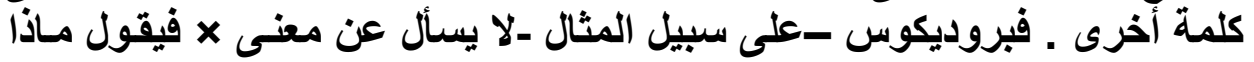

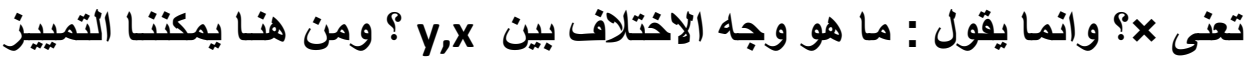

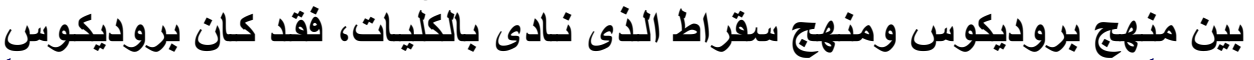

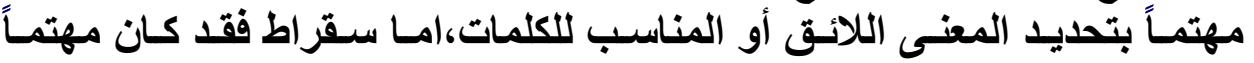

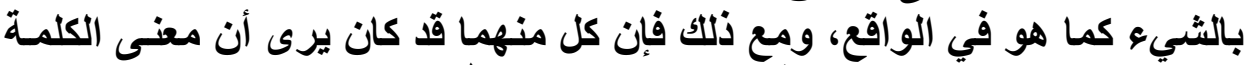

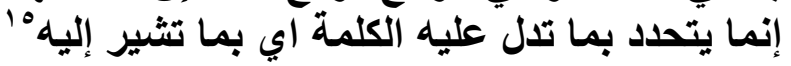
إذن هناك تشابه كبير بين عمل بروديكوس هذا وبيه

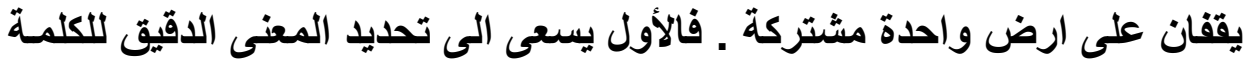

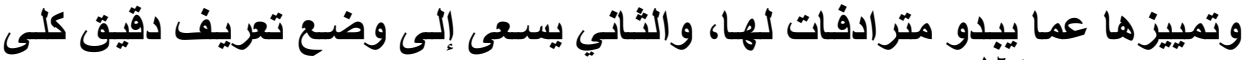

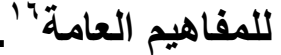
وفى محاورة بروتاجوراس يقول سقراط " والآن اذا لم أكن مخطئاً فإنك لا

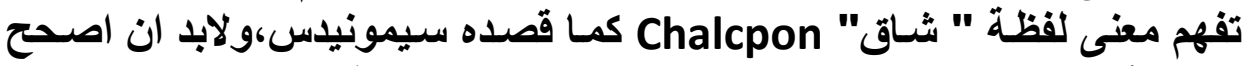

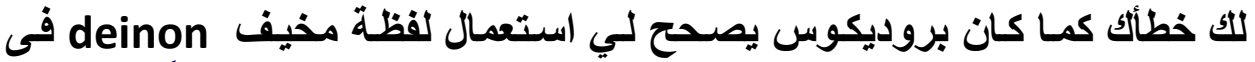

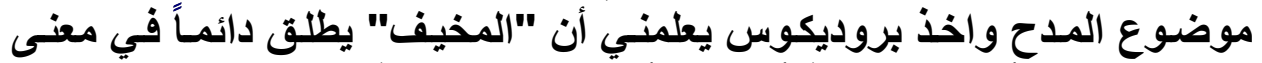

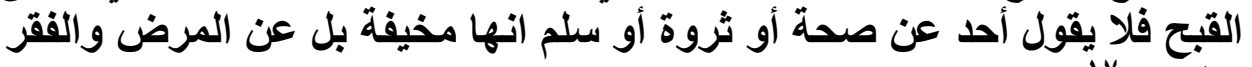

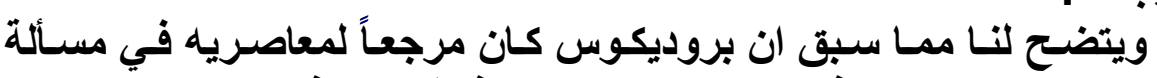

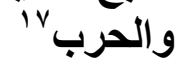

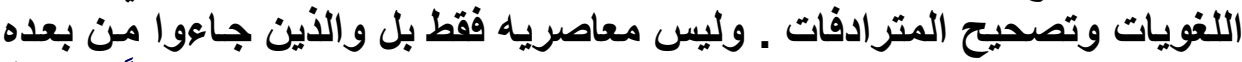

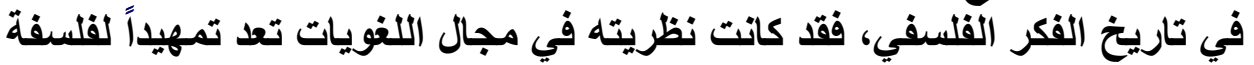

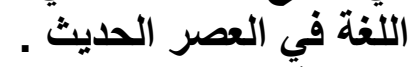
فقتّ كاتت لتبلك المحاولات التي قام بها بروديكوس في مجال اللغة اثر كبير

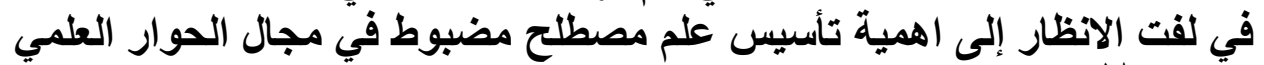

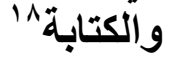

${ }^{15}$ G.B Kerferd:- The Sophistic movement, Cambridge university press,London,1984, p.74

7' محمود مر اد : فلسفة التنوير لدى السفسطائيين، دار الوفاء لدنيا الطباعة والنشر، الاسكندرية،

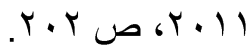

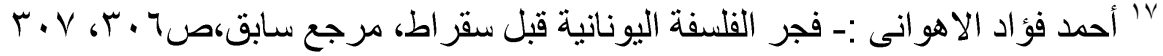
${ }^{18}$ K. Freeman: the pre-Socratic philosophers, P.372. 


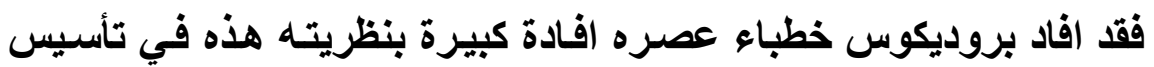

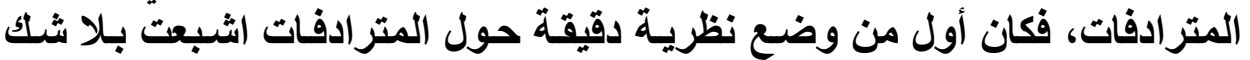

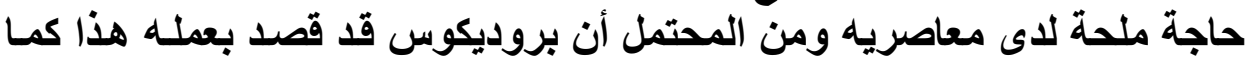

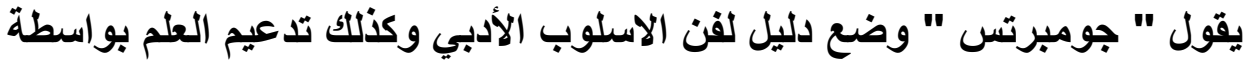

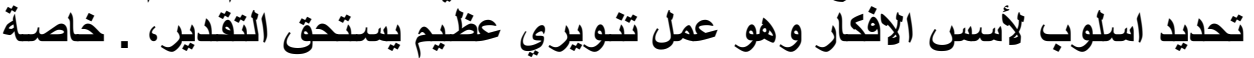

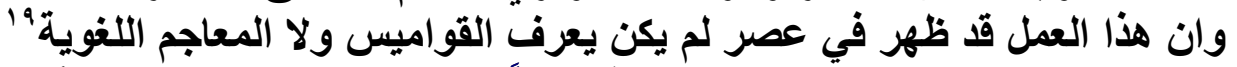

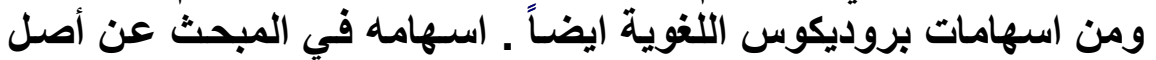

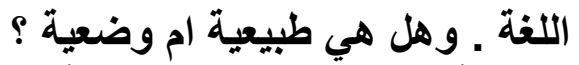
فقد تناول بروديكوس الثذرة وفيعة والوحيدة التي وصلتنا من كتابه "عن طبيعة

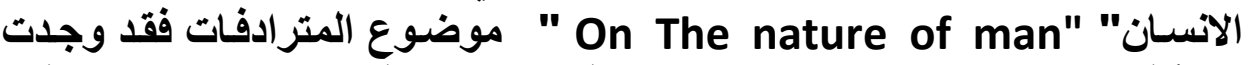

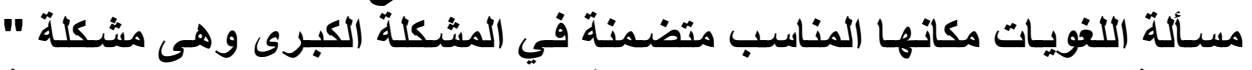

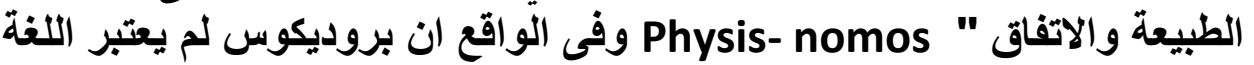

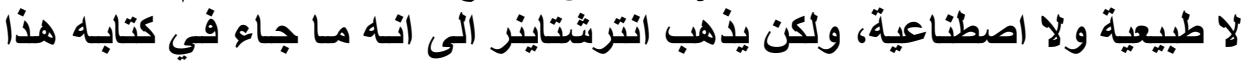

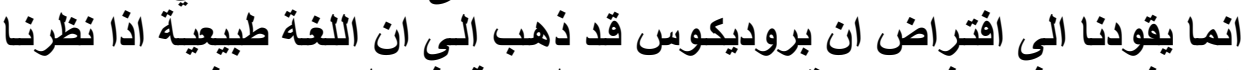

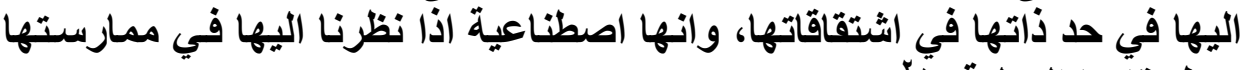

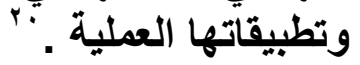

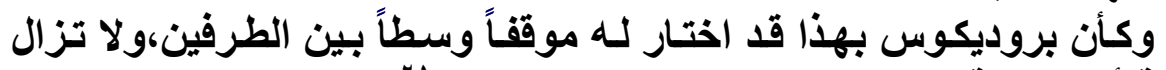

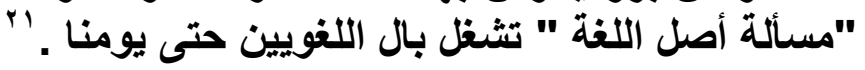

ثالنا : التمليل اللغوي لمفهوم الالوهية عند بروديكو بسر:

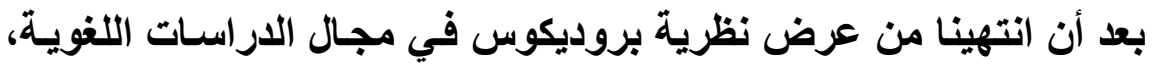

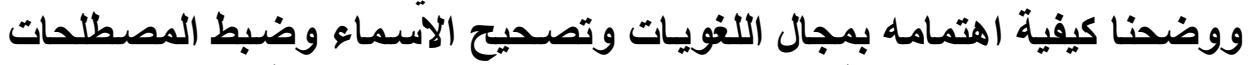

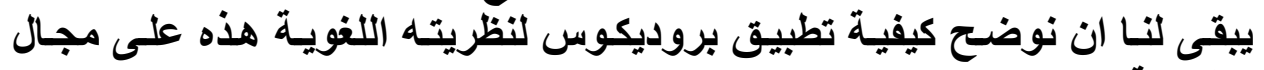

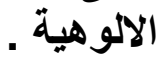

فقد تناول بروديكوس قضية الالوهية من منظور لغوى يتمثل في تحليله

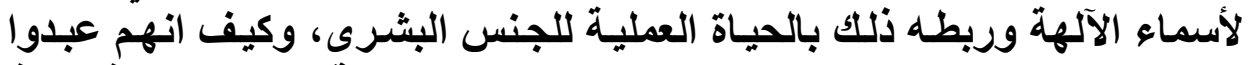

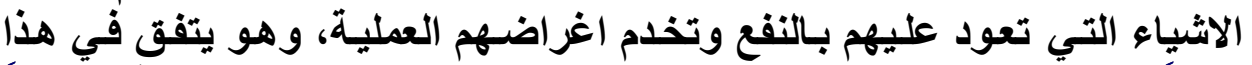

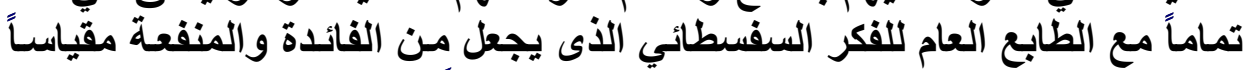

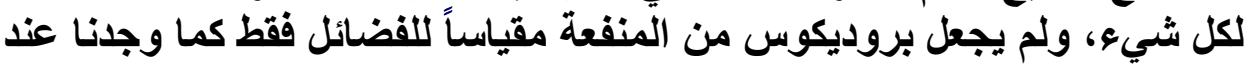

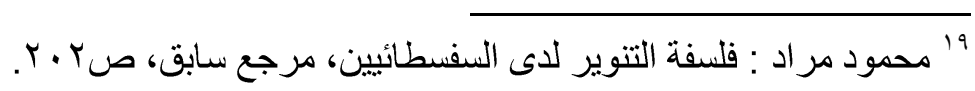

${ }^{20}$ 'M.Untersteiner: The Sophists, trans by ;K. freeman .Basil black well,Oxford,1954, P.213. 
مجلة كلية الآداب، جامعة سوهاج، العدد الخمسون، الجزء الثاني، يناير 9 1 ـ بم

بروتـاجوراس وغيره مـن السفسطائيين وانمـا امتـدت عنـــه لمجـال الالوهيـة والعقائد الاينية .

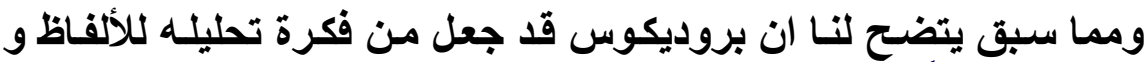

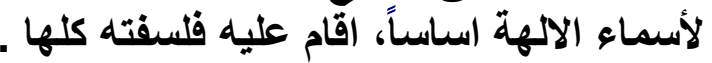

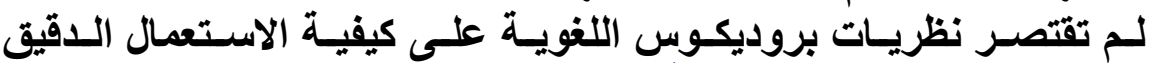

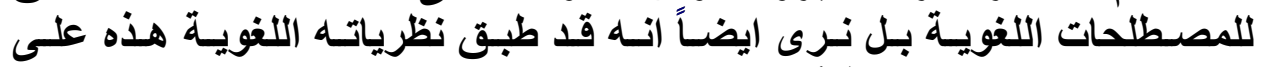

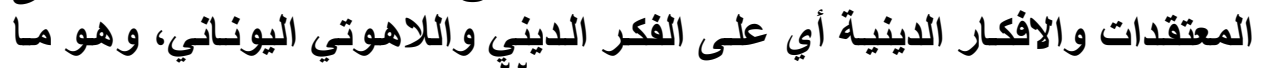

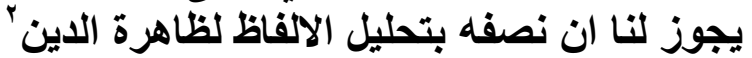

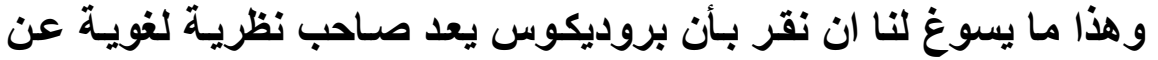

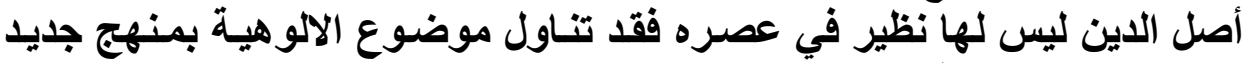

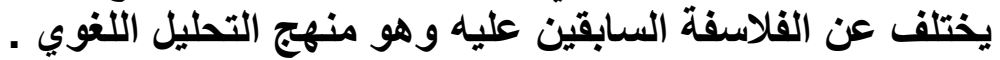

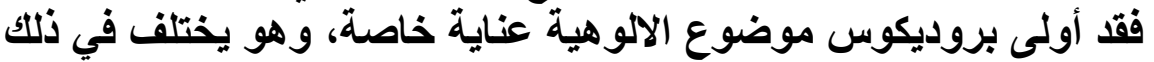

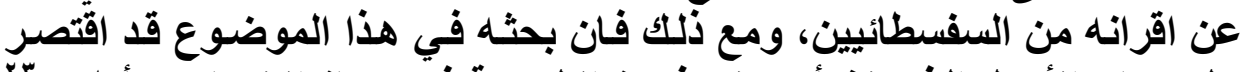

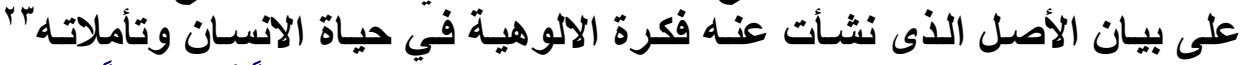

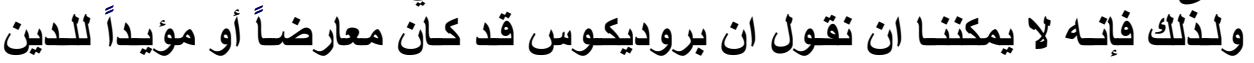

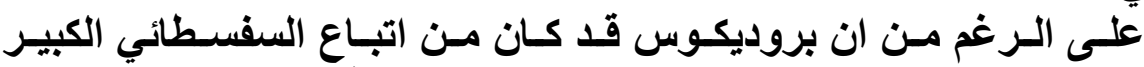

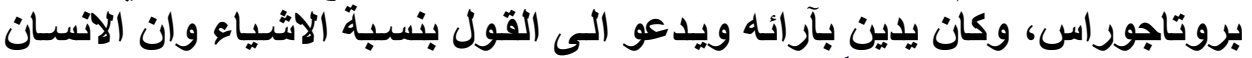

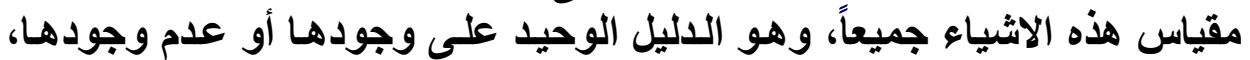

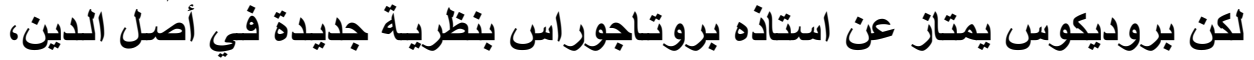

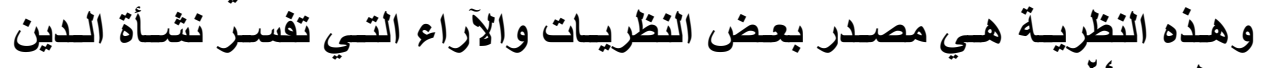
وتطويره و ومده

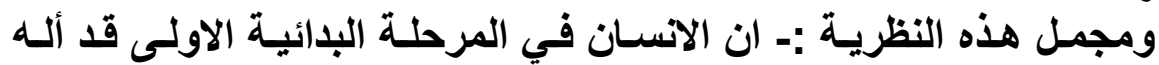

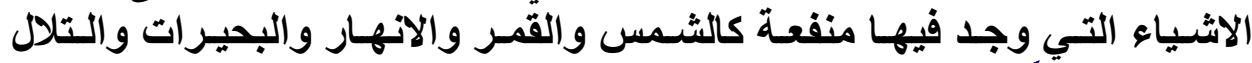

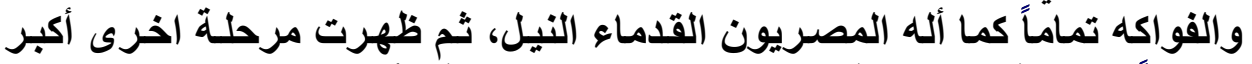

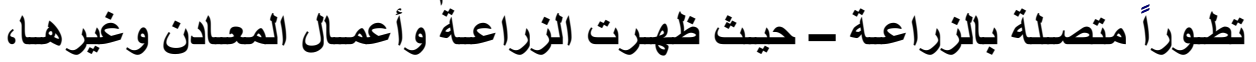

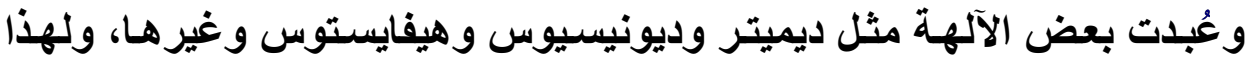

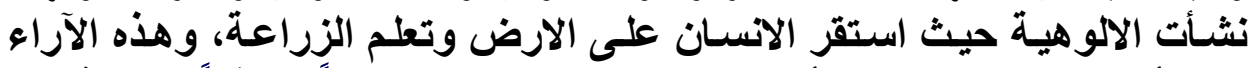

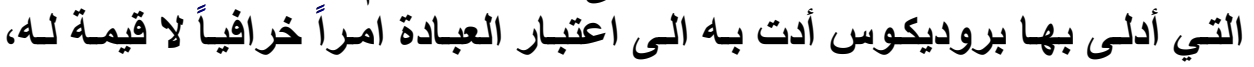

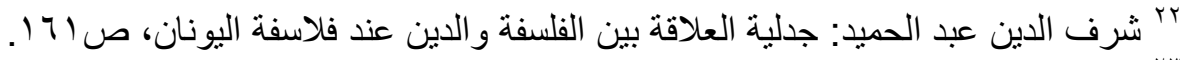

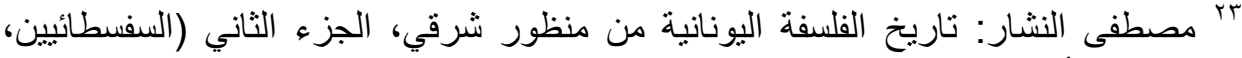

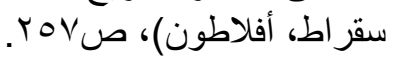

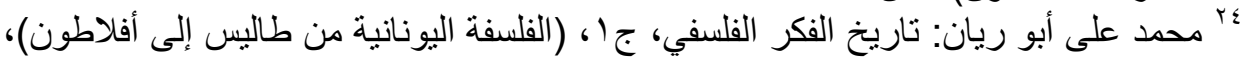

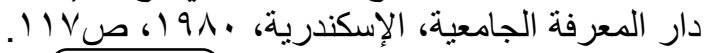

19. 
وبسب ذلك دخل في صراع مع السلطات الأثينية ممـا أدى الى إدانته وطرده من

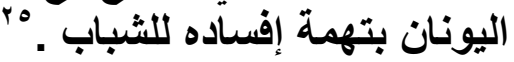

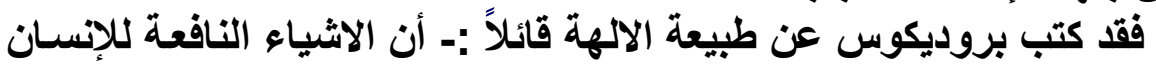

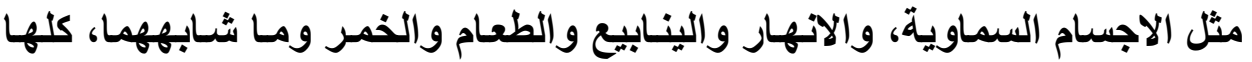

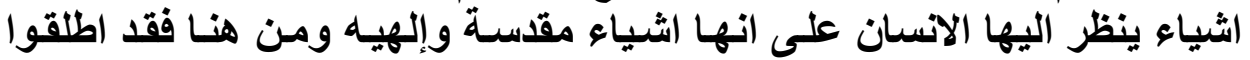

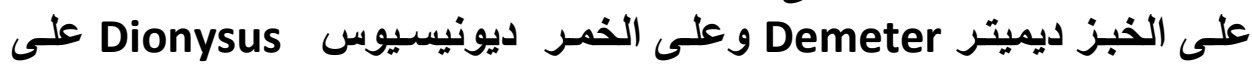

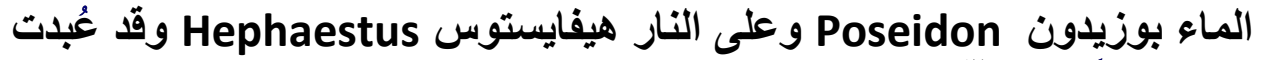

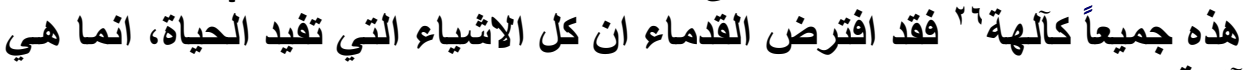

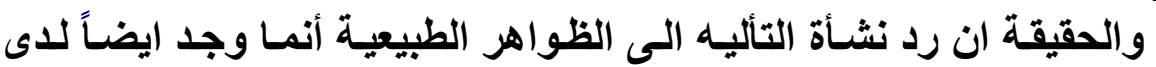
آلهة .

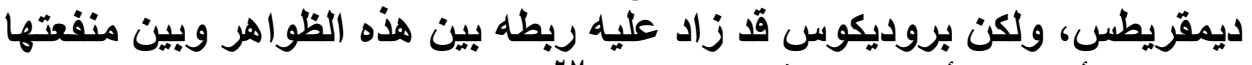

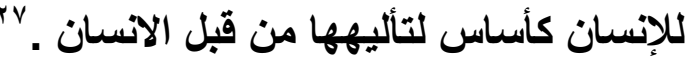

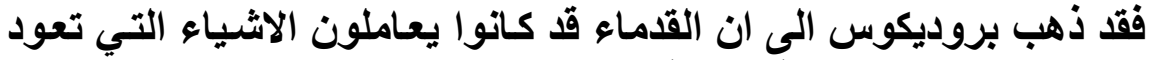

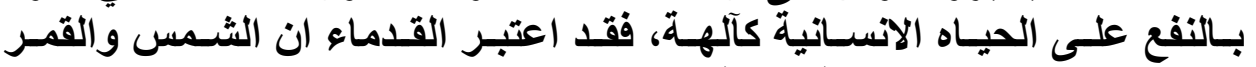

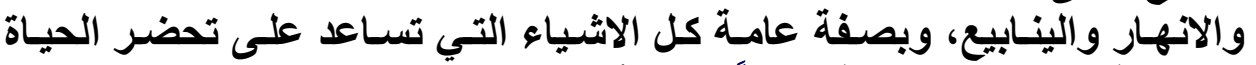

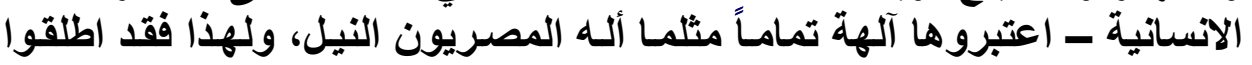

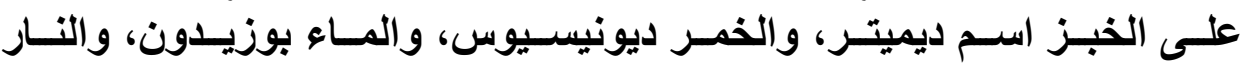

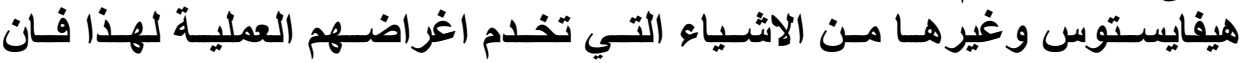

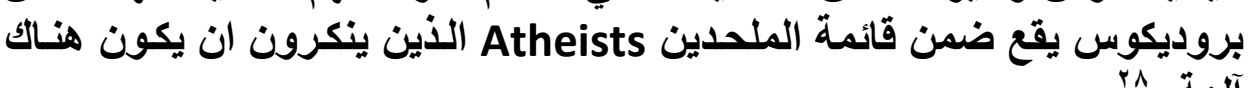

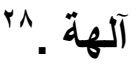
فقد أدى تحليل الألفاظ ببروديكوس إلى القول بالفيتشية حيث كان النساس

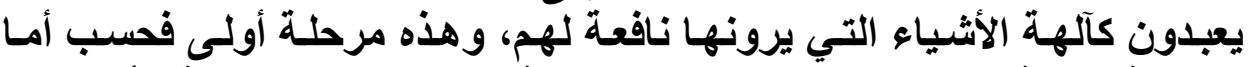

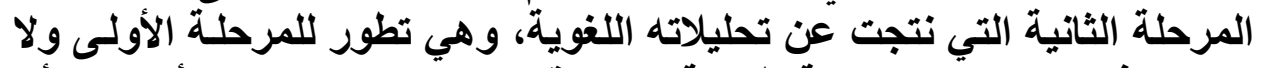

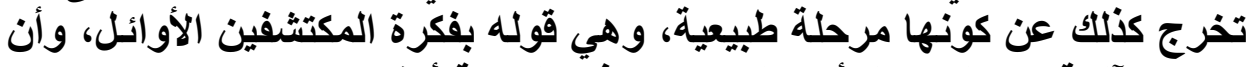

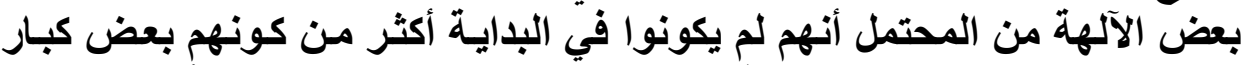

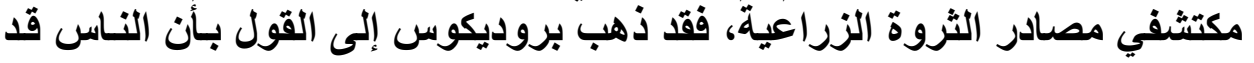

• حربي عباس عطيتو : الفلسفة القديمة من الفكر الثرقي الى الفلسفة اليونانية، مرجع سابق، ص rov

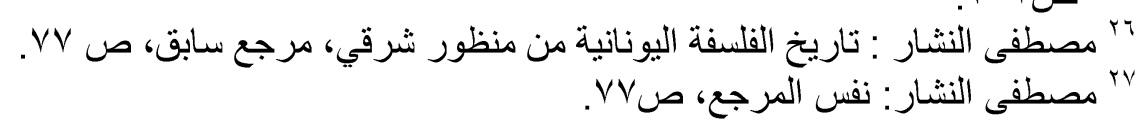
${ }^{28}$ W.K. Guthrie: The Sophists, Cambridge university press,Newyork,1988, p.238. 


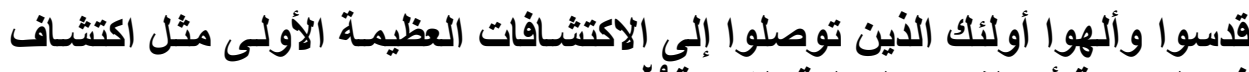

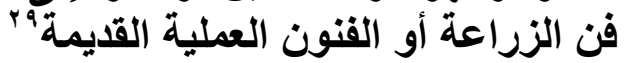
فقد ذهب فيلوديموس Philodemus (وهو أبيقورى من القرن الأول) إلى الى الإن

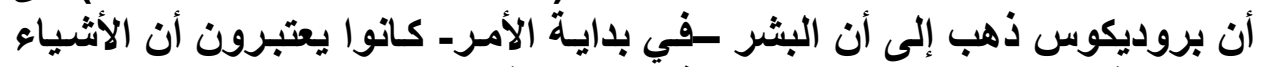

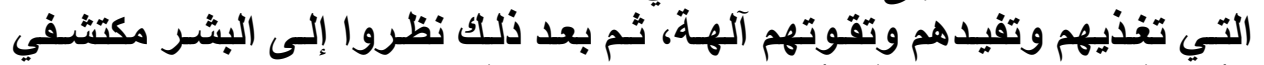

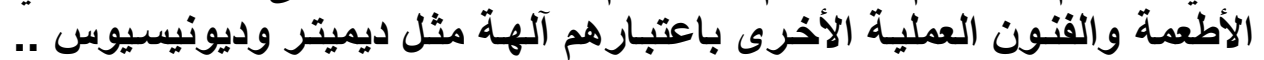

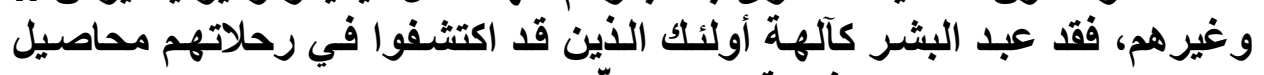

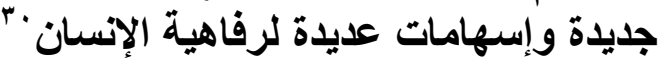

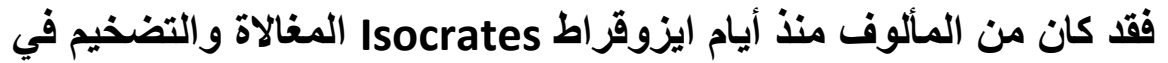

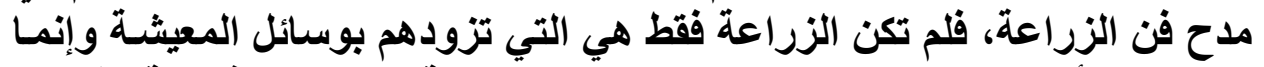

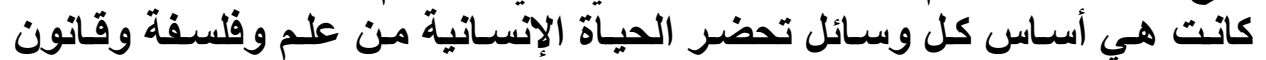

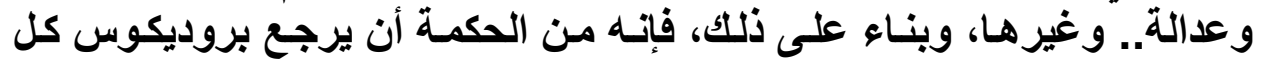

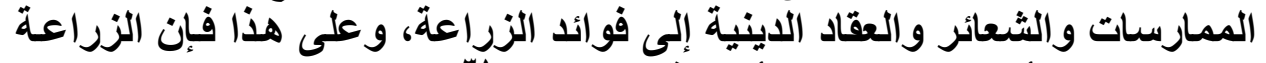

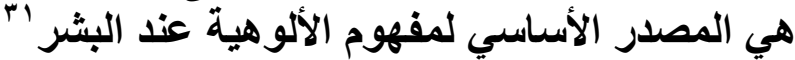

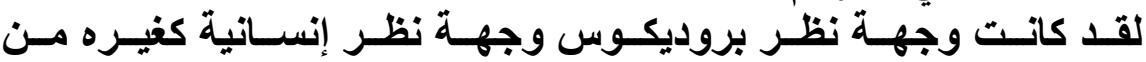

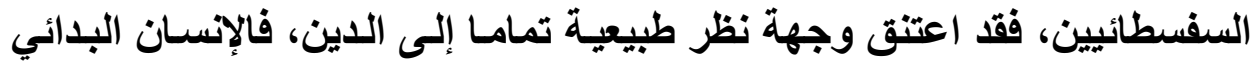

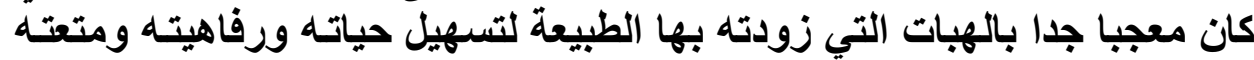

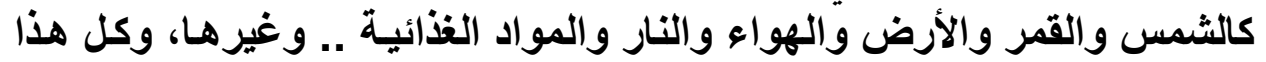

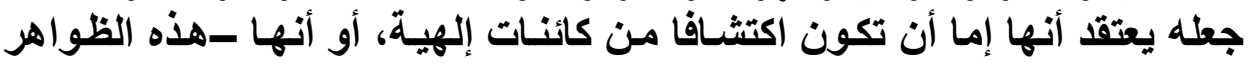

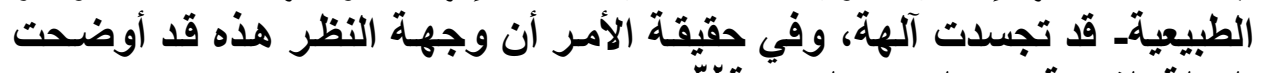

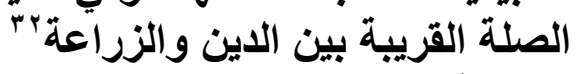

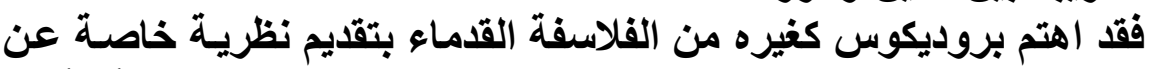

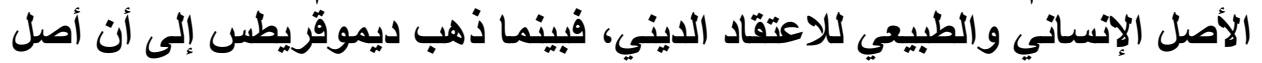

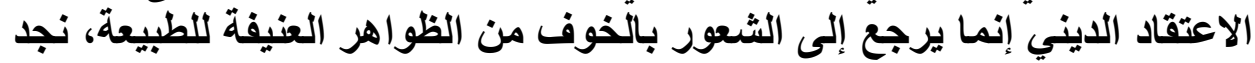

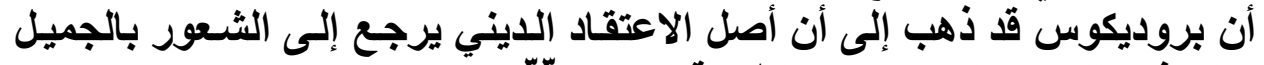

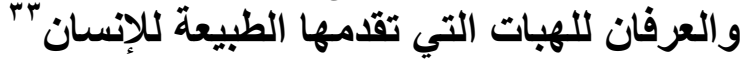

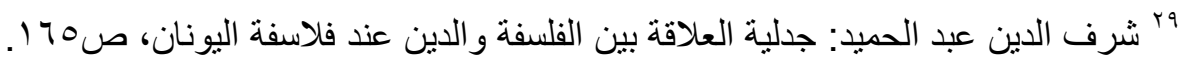
30 W.K.Guthrie: The Sophists, p.237.

${ }^{31}$ Ibid , P.239.

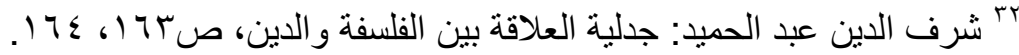
${ }^{33}$ W.K.Guthrie: optic, P.237. 


\section{رابعا :- علاقة فكرة الالوهية بـالمجتمع عند بروديكوسر:}

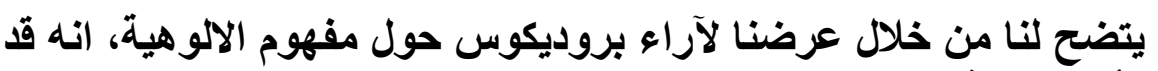

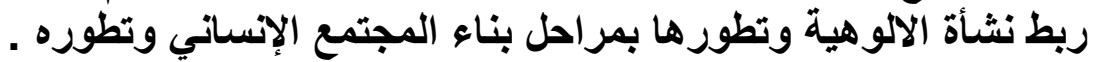

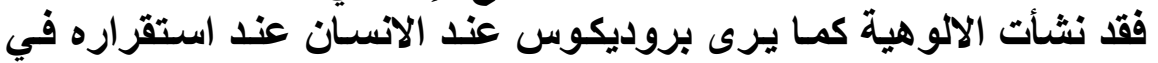

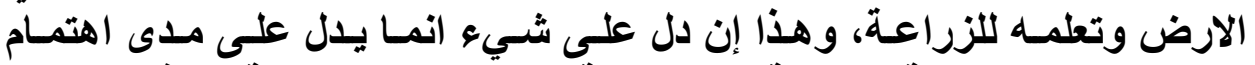

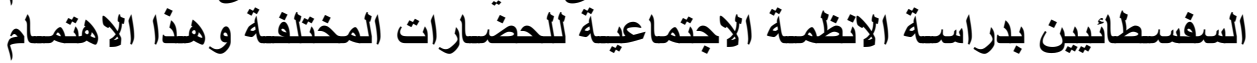

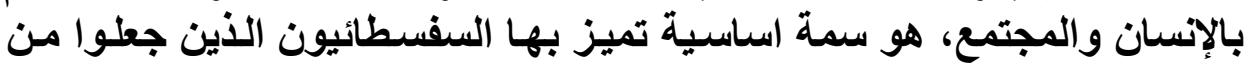

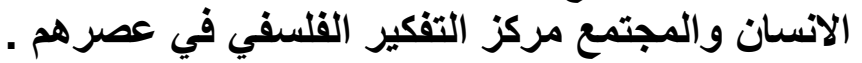

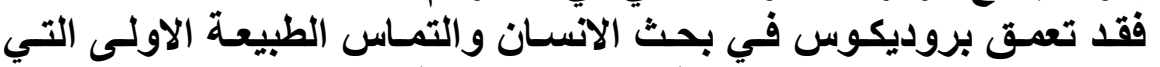

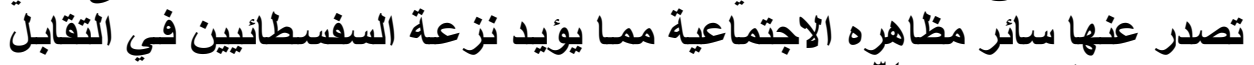

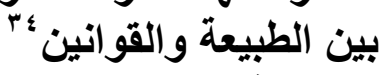

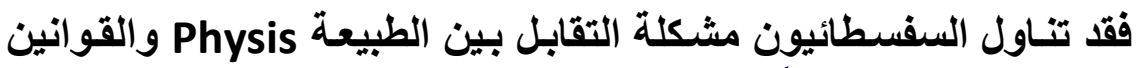

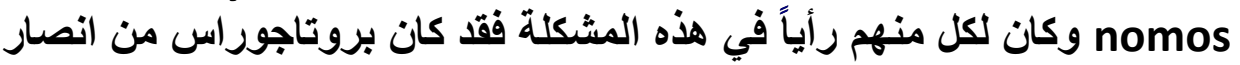

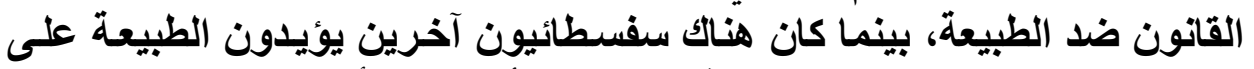

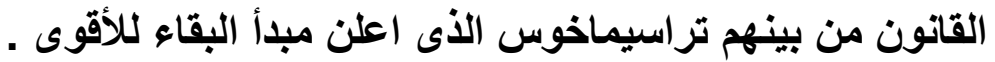

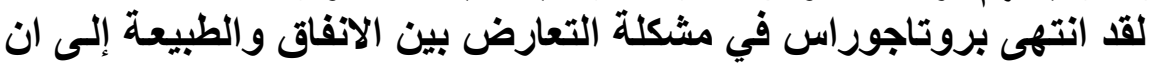

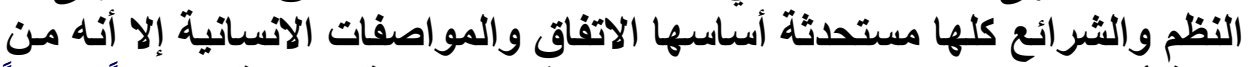

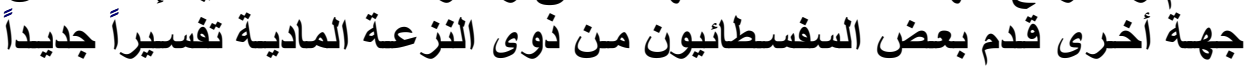

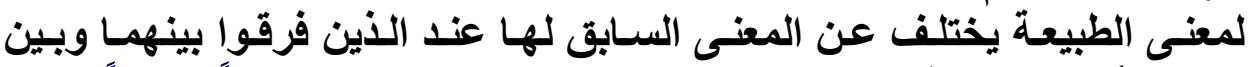

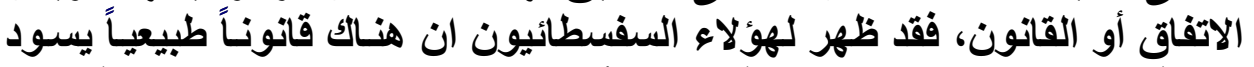

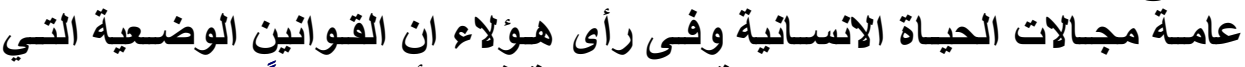

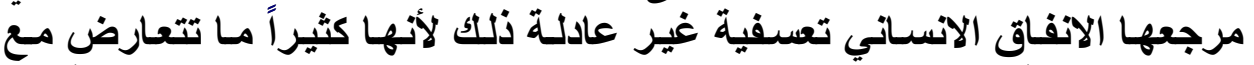

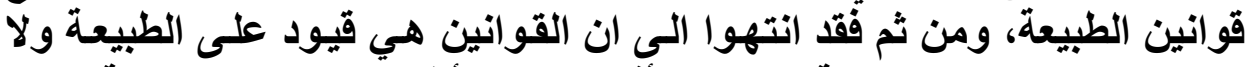

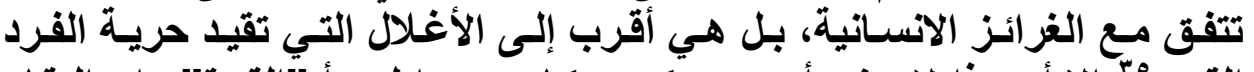

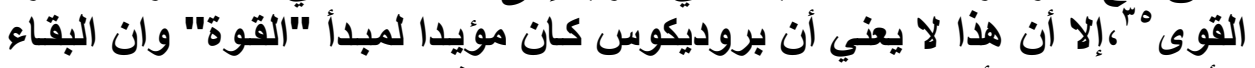

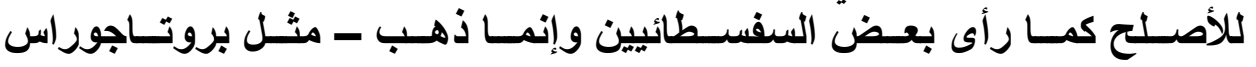

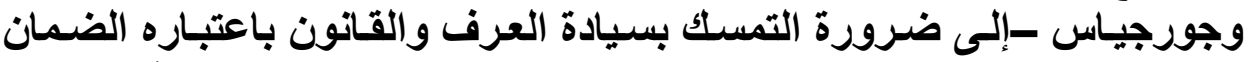

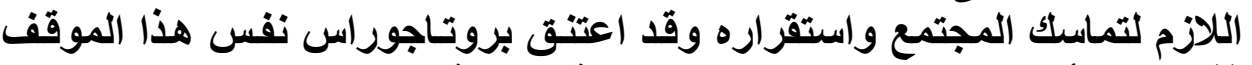

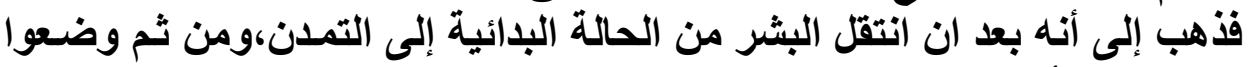

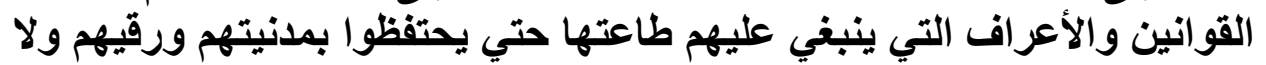

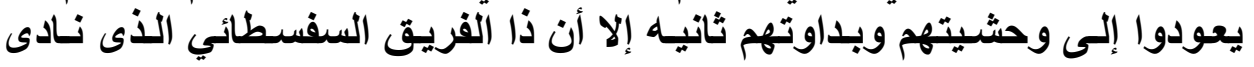

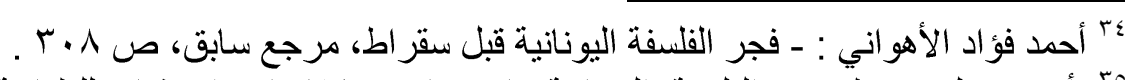

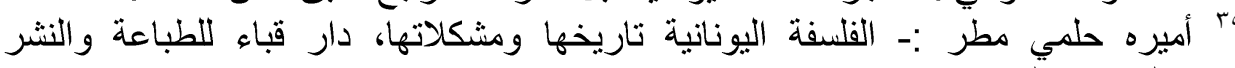


بإتباع العرف والقانون قد نادى بإتباعه لذاته لا لأنه قاتون إلهي مقدس كما كان

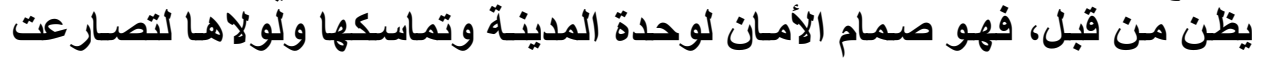

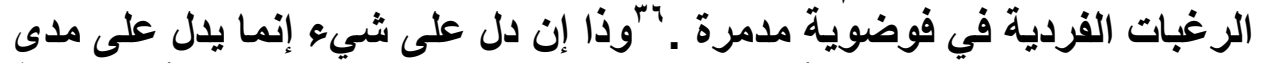

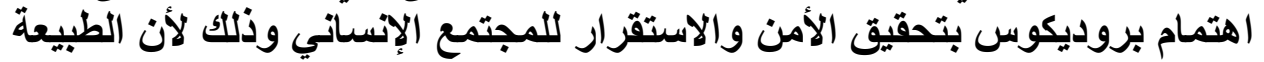

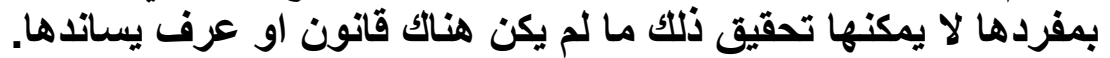

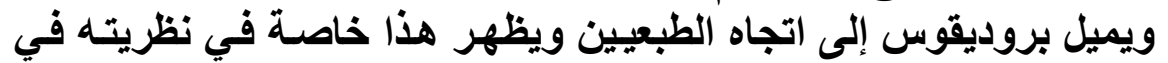

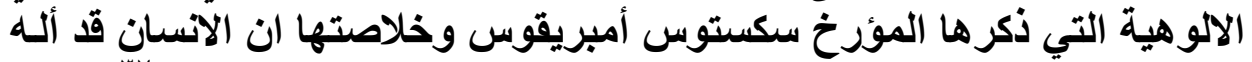

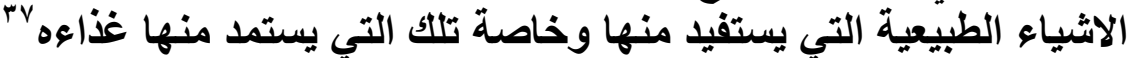

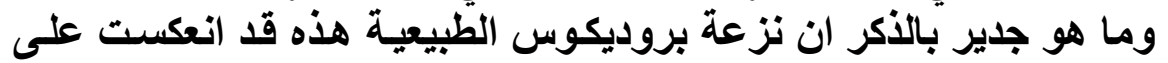

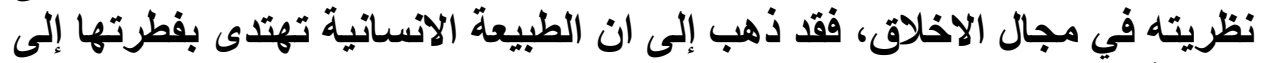
وقد لخص بروديكوس موقفـه الاخلاقي مـن خلال اسطورة هي اسطورة

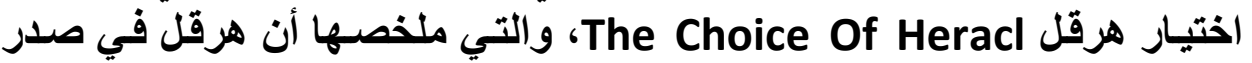

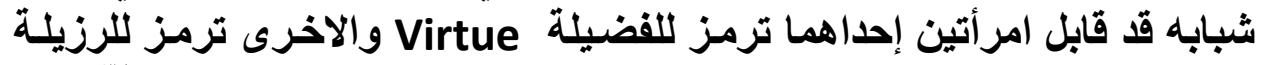

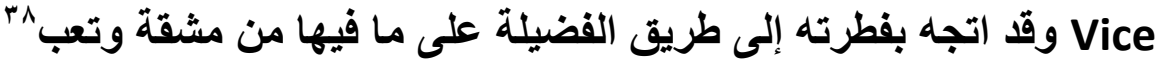

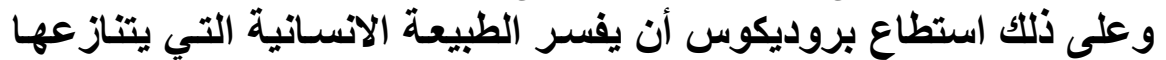

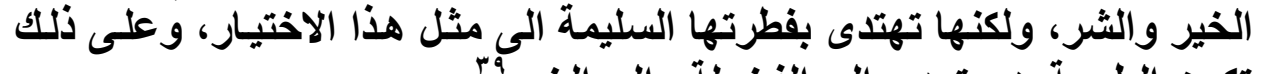

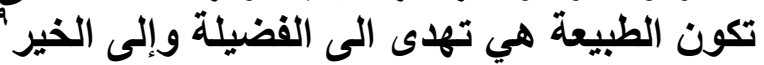

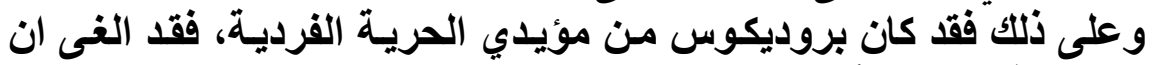

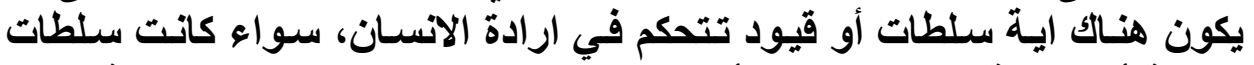

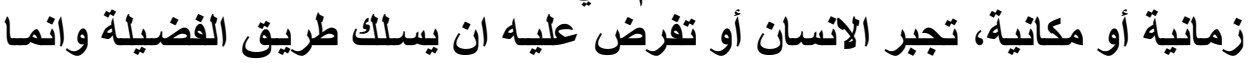

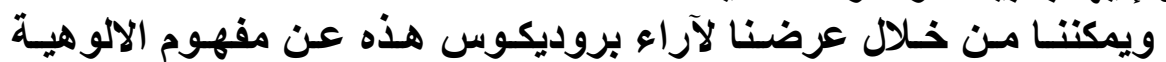

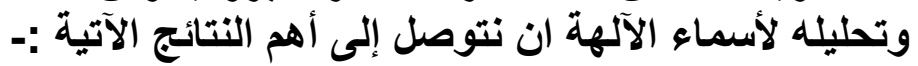

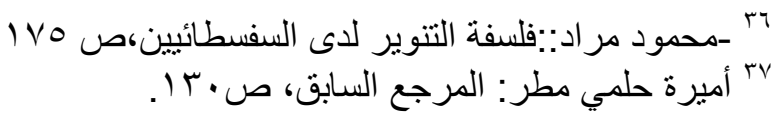

38 K.Freemman: Ancilla to the Pre- socratic philosophers, basil black well,oxford,1948, P.130 .

ج" أميرة حلمي مطر :- الفلسفة عند اليونان، الجزء الاول،دار الثقافة للنشر والتوزيع، 


\section{أ - موقهه من فكرة الفوف من الموت :-}

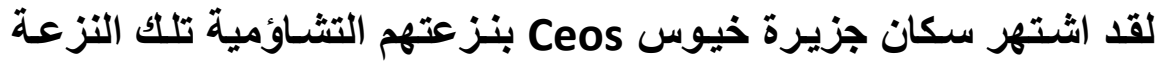

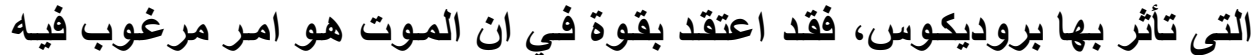

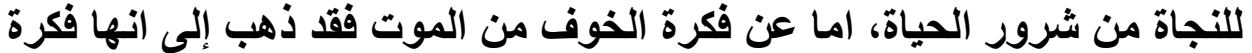

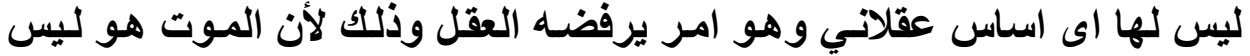

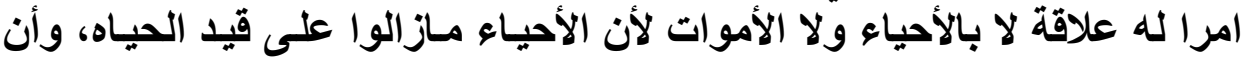

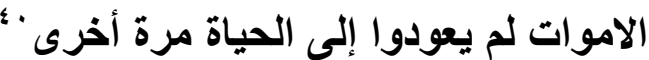

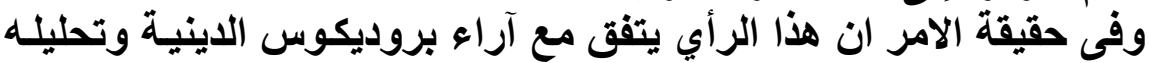

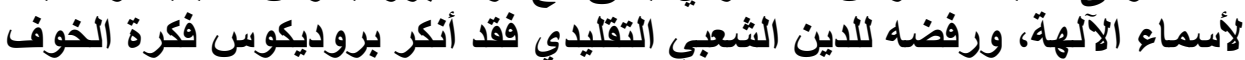

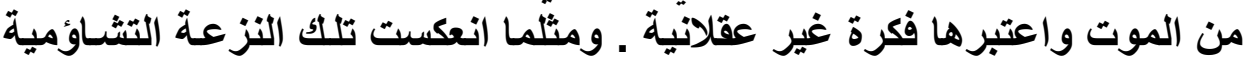

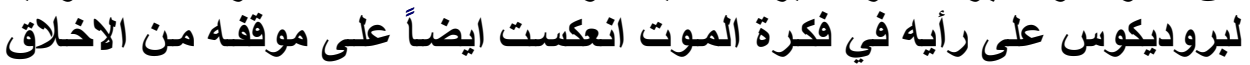

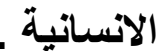

فقد كان بروديكوس يؤيد حياة الشرف والكرامة والكدح والتعب على حياة

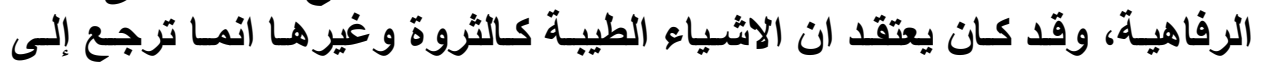

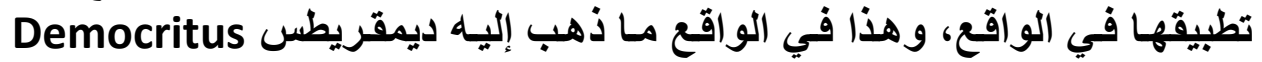

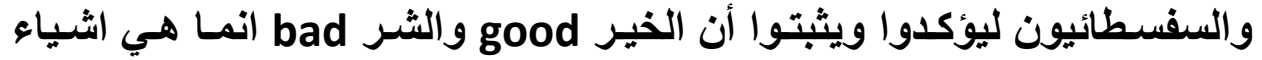

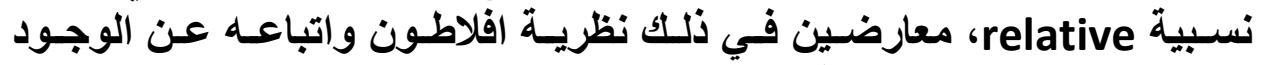
'المطلق Absolute good

\section{ب - موقهنه من فكرة الملاةة والقرابين :-}

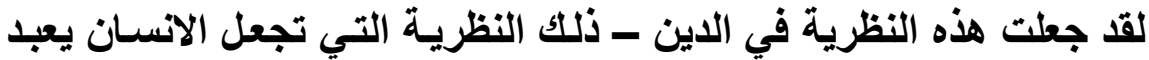

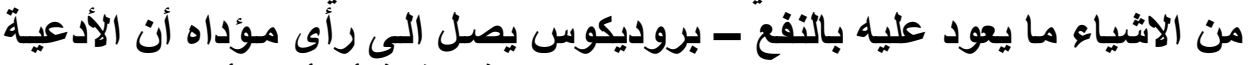

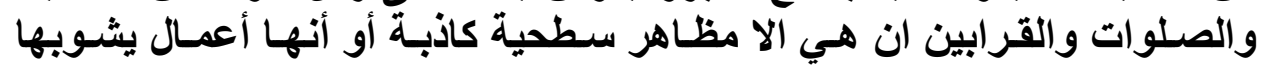

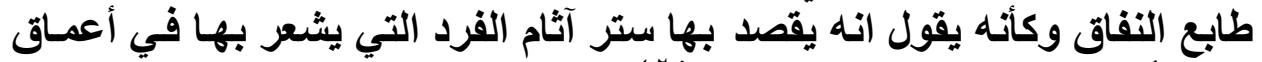

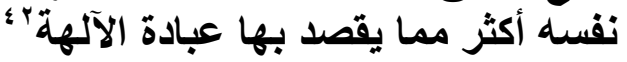

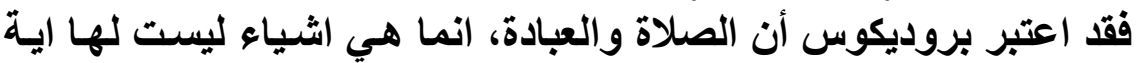

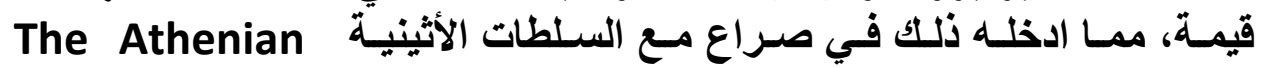

•؛ شرف الدين عبد الحميد: جدلية العلاقة بين الفلسفة والدين عند فلاسفة اليونان، ص7و 197 . ${ }^{41}$ K.Freeman :- The pre-Socratic philosophers.P.373 .

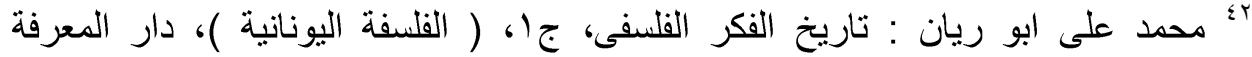


The schoole وقيل انسه نُفى أو طرد مـن مدرسـة اللوقيوم authorities

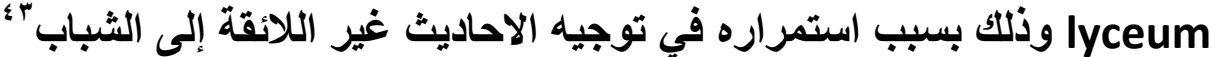

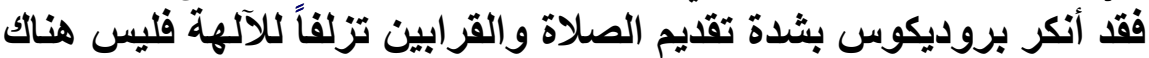

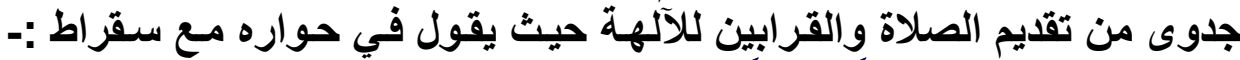

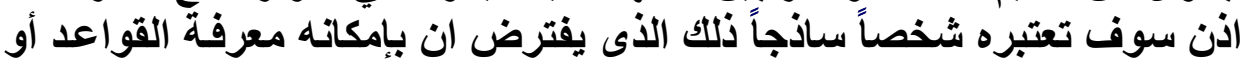

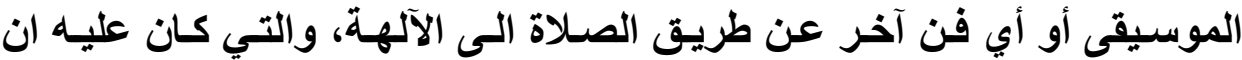

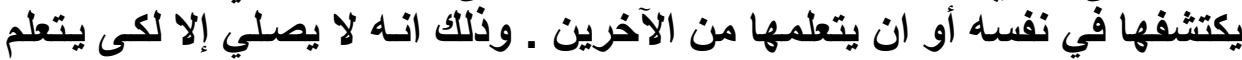

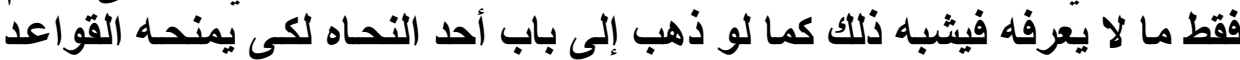

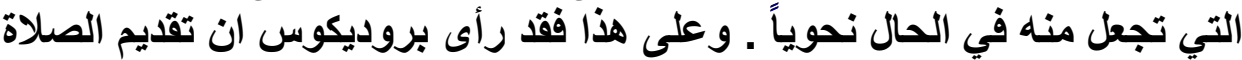
والقرابين ما و إلاً نوع من الن النفاق والئ والمخاتلة.

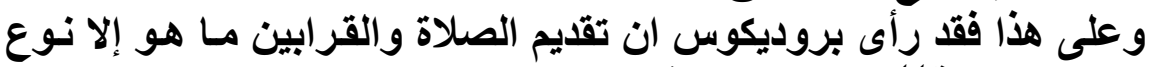

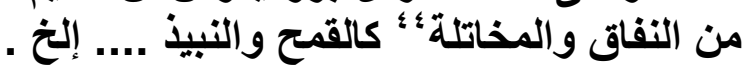

\section{م - موقهه مز العناية الإلهية :-}

لقد حاول بروديكوس أن يوفق بين الدين الثعبي المألوف وبين القائ القلسفة

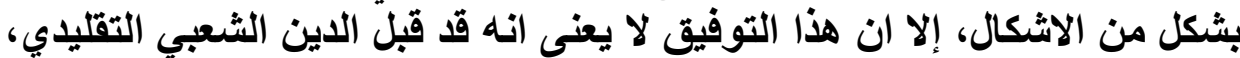

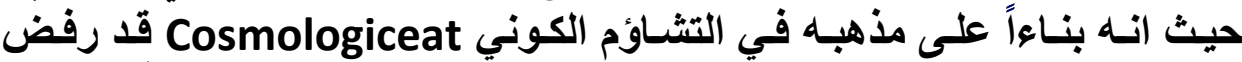

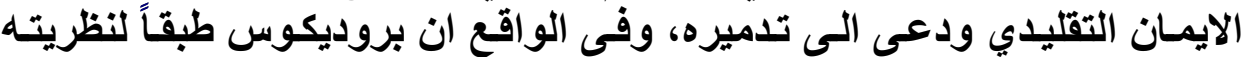

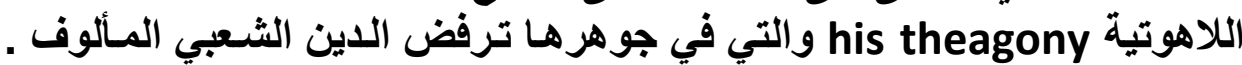

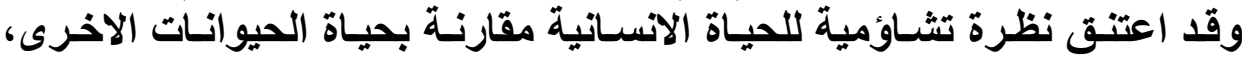

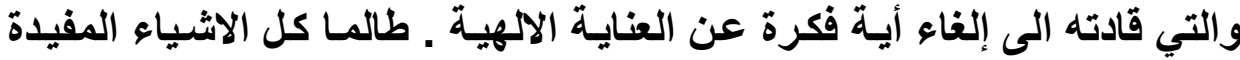

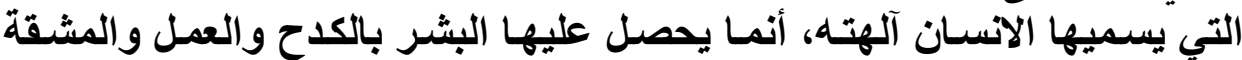

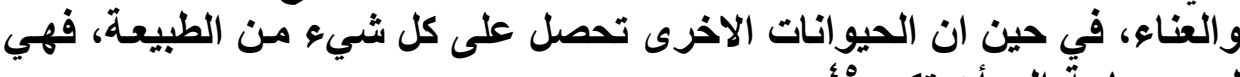

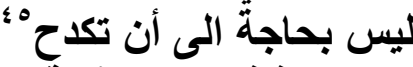

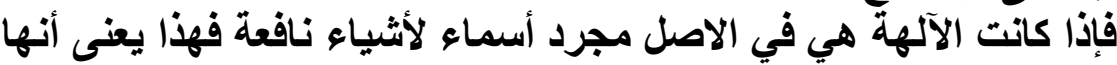

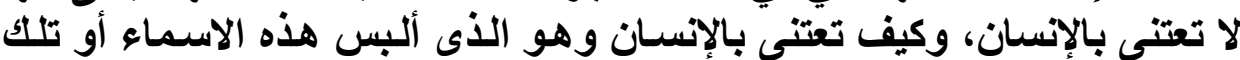

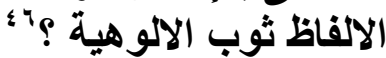

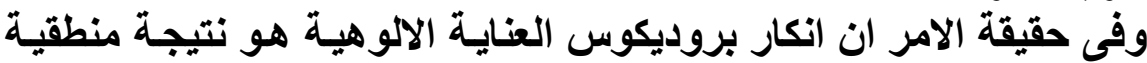

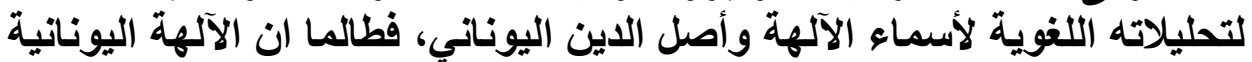

${ }^{43}$ E.zeller: Outline Of The history Of Greek philosophy, Dover publication inc ,1980, p.102.

؛ شرف الدين عبد الحميد: جدلية العلاقة بين الفلسفة والدين عند فلاسفة يونان، ص1717 ا.

${ }^{45}$ Untiesteiner: The sophists, p.211 .

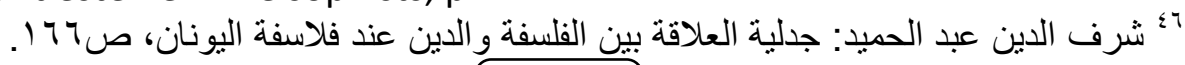




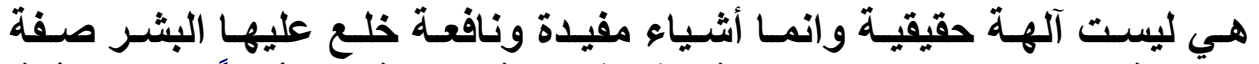

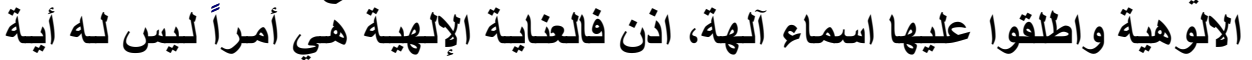

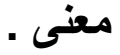

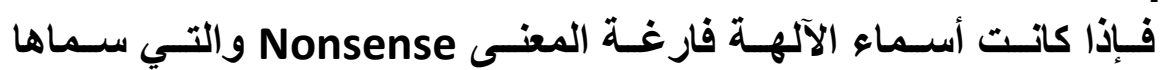

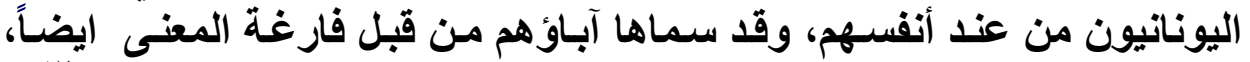

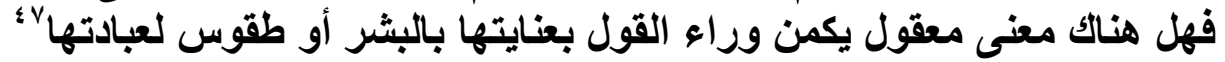

\section{خامسا: نـنائم البحثْ: -}

ومما سبق عرضه يمكنتا أن نستنتج ما يالي:-

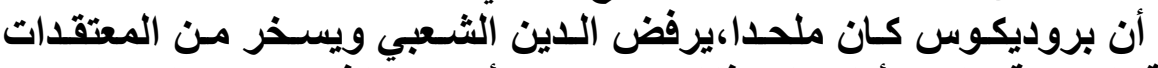

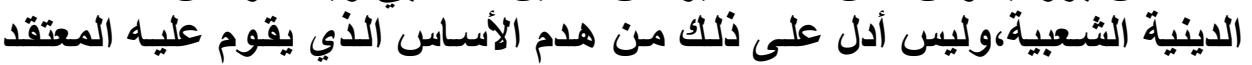

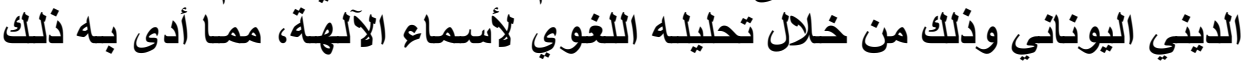

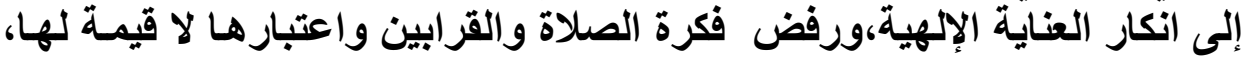

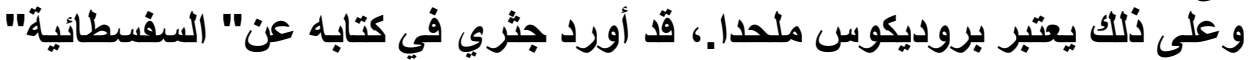

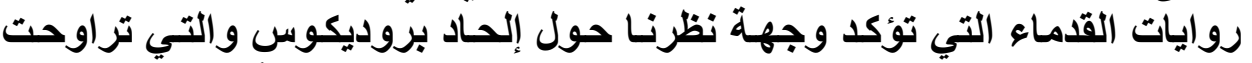

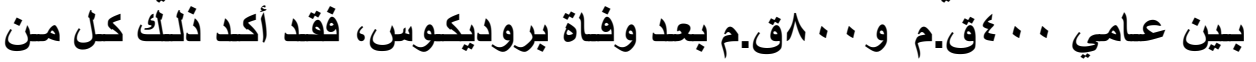

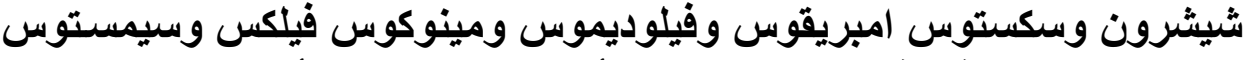

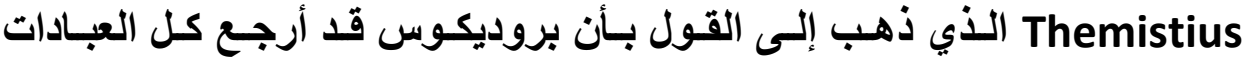

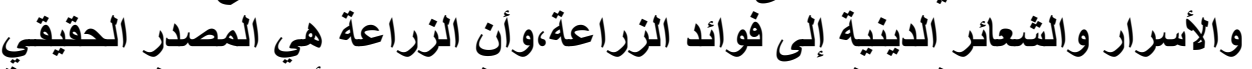

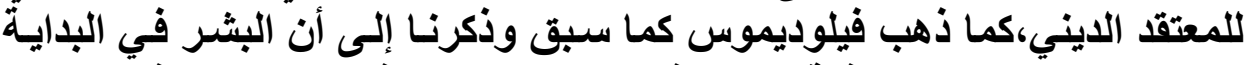

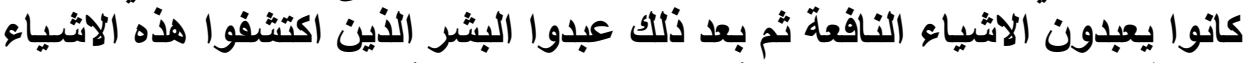

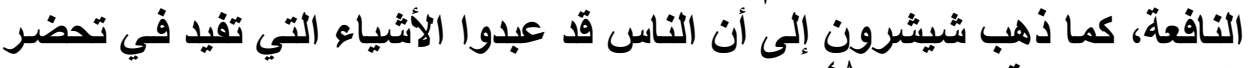

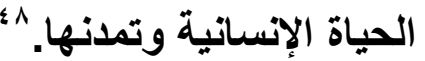
وعلى الرغم من تواتر هذه الروايات الكثيرة حول إلحاده، إلا أنتا نجد أحد ألداند

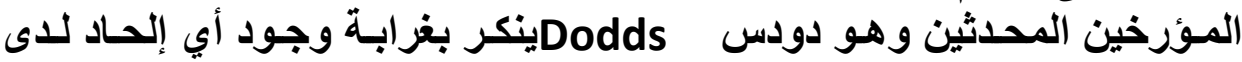

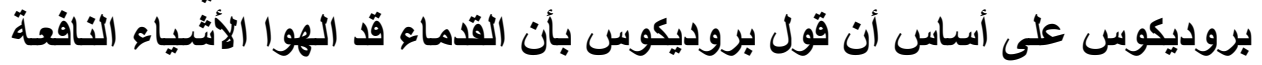

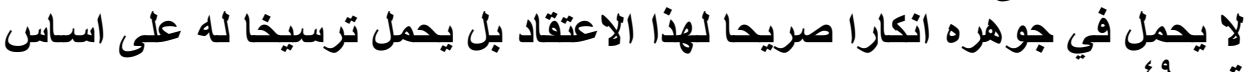
قوي ؛

في الواقع أنتا لا نتفق مع دودس في هذا الرأي لأن هذا التأويل لرأي مفكر

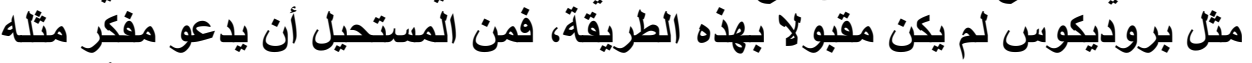

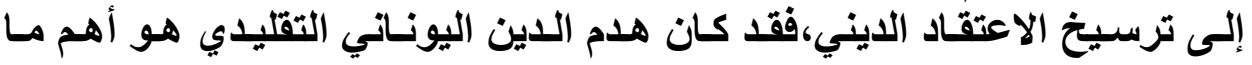

كV شرف الدين عبد الحميد: جدلية العلاقة بين الفلسفة والدين عند فلاسفة اليونان، ص17 178 . ${ }^{48}$ Guthrie ;The Sophists, p.238

9؛ محمود مر اد فلسفة التنوير لاى السفسطائيين،صب • 1. 


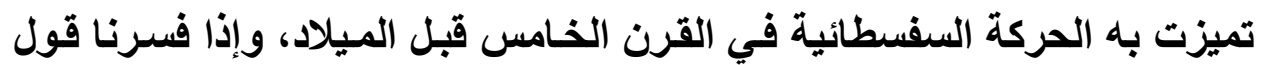

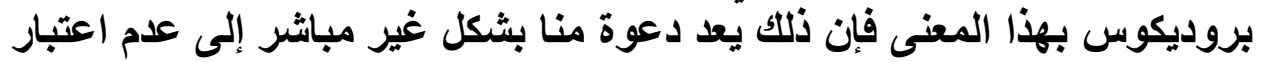

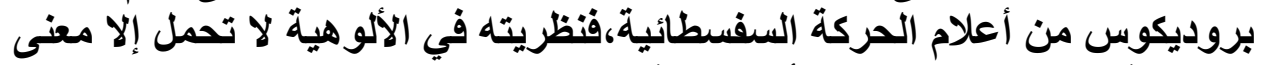

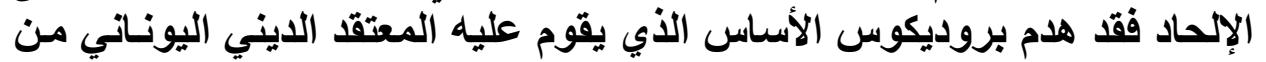

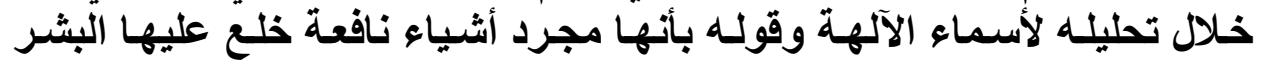

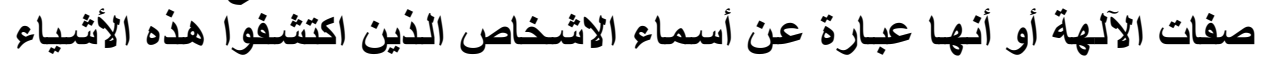

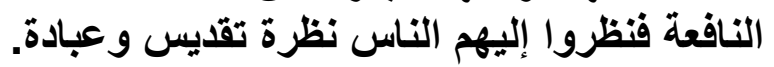

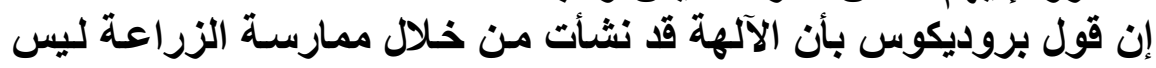

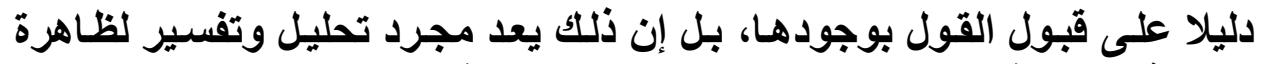

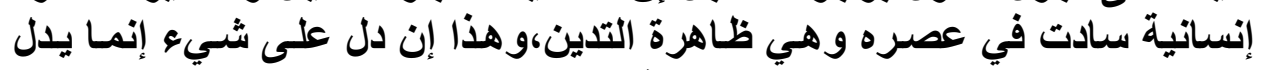

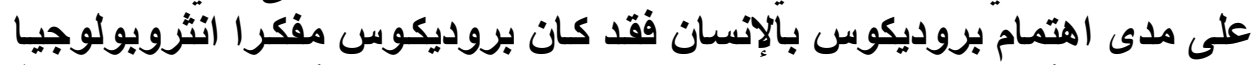

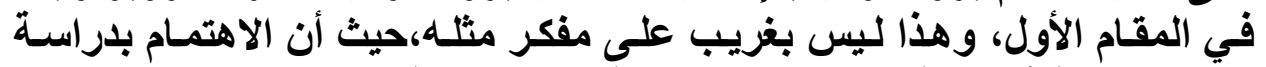

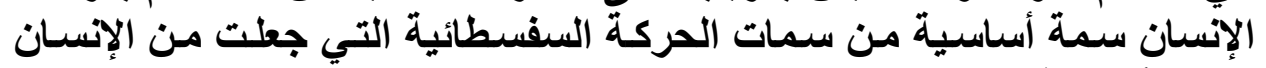

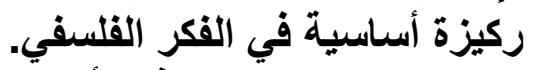

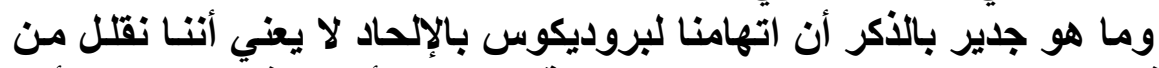

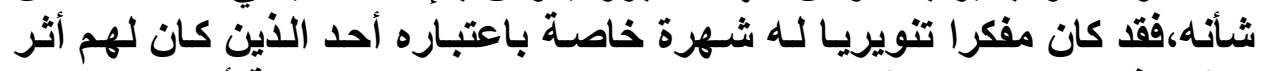

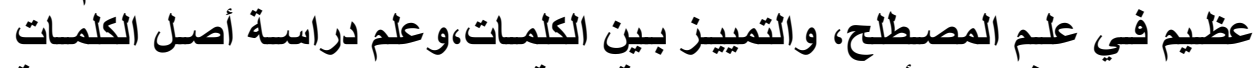

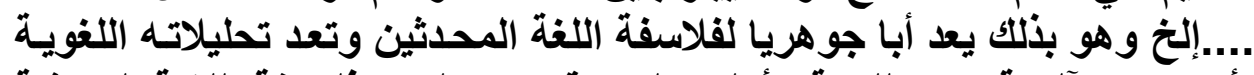

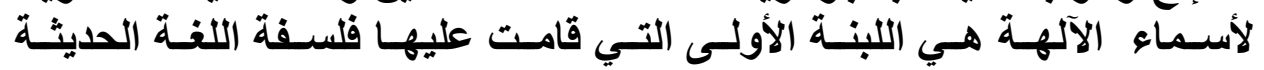
والمعاصرة. 


\section{قائمة المصادر والمراجز}

\section{أولا: المصادر والمراجم العربية:}

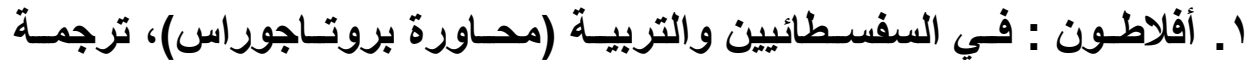

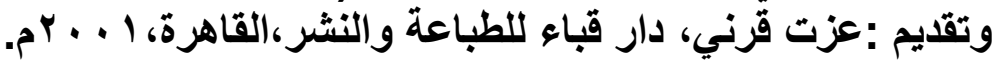

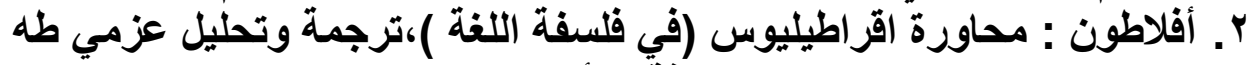

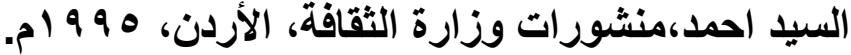

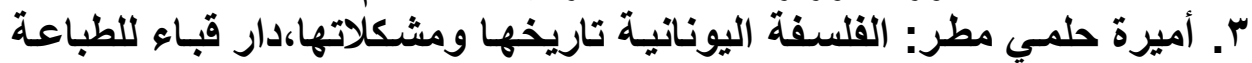

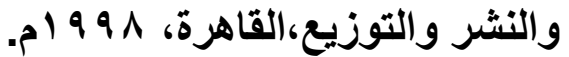

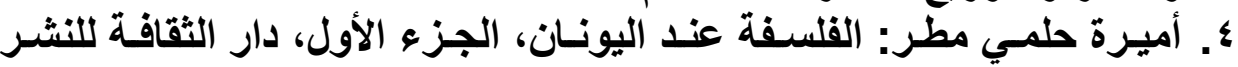

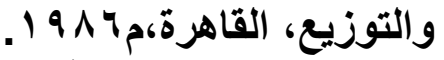

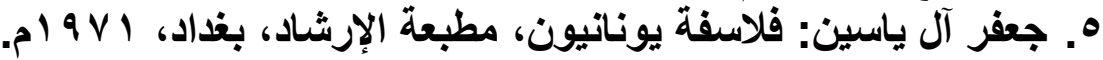

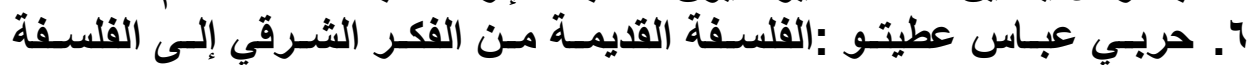

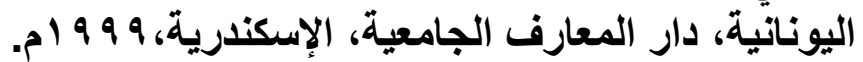

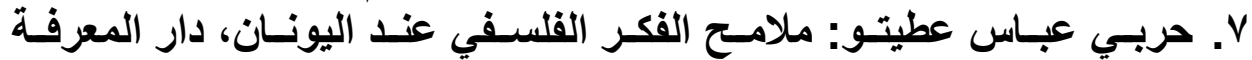

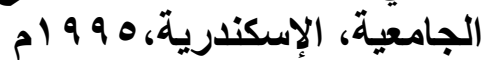

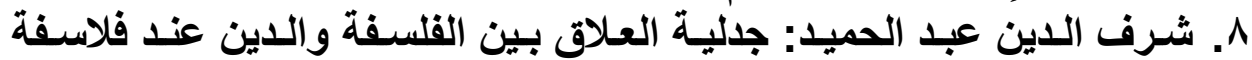

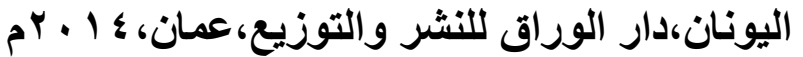

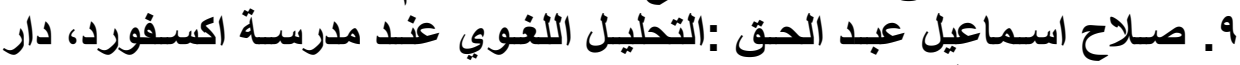

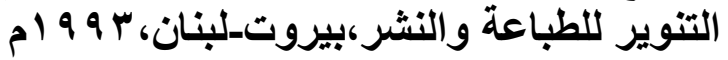

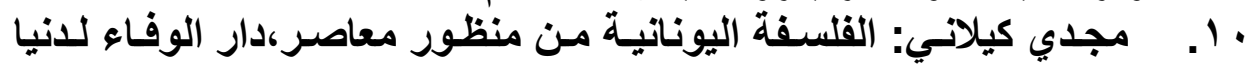

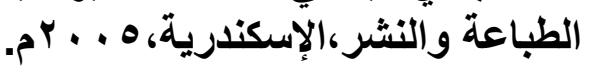

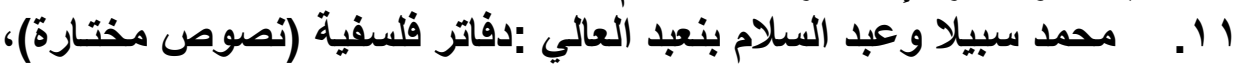

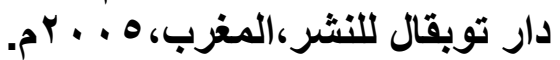

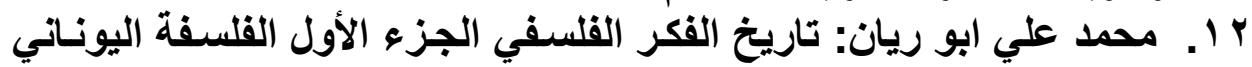

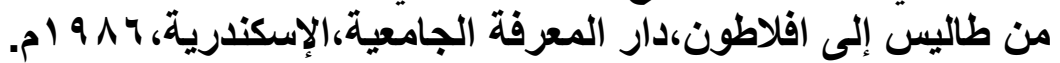

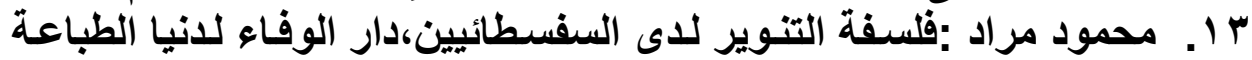

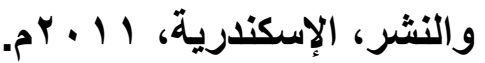

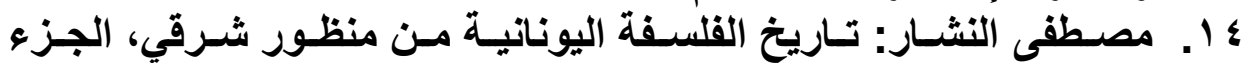

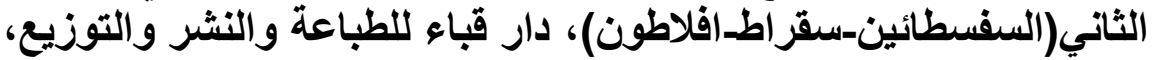

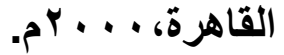




\section{ثنانبا :المراجر الإنجليزبة:}

1-E.zeller: Outlines of the history of Greek philosophy , Dover publication inc ,new york ,1980.

2-G.B.Kerferd; The sophistic movement ,Cambridge university press,London,1984.

3-K.Freeman ;Ancilla the pre-socratic philosophers,basil black well , Oxford, 1948.

4; the pre-socratic philosophers,basil black well , Oxford, 1959.

5-unterstiener ;the sophists ,trans by: K.freeman ,basil black well, oxford .1954.

6-W.K.Guthrie;the Sophists, ,Cambridge university press ,New- york,1988.. 